\title{
Bacterial extracellular electron transfer: a powerful route to the green biosynthesis of inorganic nanomaterials for multifunctional applications
}

\author{
Long Zou, Fei Zhu, Zhong-er Long and Yunhong Huang ${ }^{*}$
}

\begin{abstract}
Synthesis of inorganic nanomaterials such as metal nanoparticles (MNPs) using various biological entities as smart nanofactories has emerged as one of the foremost scientific endeavors in recent years. The biosynthesis process is environmentally friendly, cost-effective and easy to be scaled up, and can also bring neat features to products such as high dispersity and biocompatibility. However, the biomanufacturing of inorganic nanomaterials is still at the trialand-error stage due to the lack of understanding for underlying mechanism. Dissimilatory metal reduction bacteria, especially Shewanella and Geobacter species, possess peculiar extracellular electron transfer (EET) features, through which the bacteria can pump electrons out of their cells to drive extracellular reduction reactions, and have thus exhibited distinct advantages in controllable and tailorable fabrication of inorganic nanomaterials including MNPs and graphene. Our aim is to present a critical review of recent state-of-the-art advances in inorganic biosynthesis methodologies based on bacterial EET using Shewanella and Geobacter species as typical strains. We begin with a brief introduction about bacterial EET mechanism, followed by reviewing key examples from literatures that exemplify the powerful activities of EET-enabled biosynthesis routes towards the production of a series of inorganic nanomaterials and place a special emphasis on rationally tailoring the structures and properties of products through the fine control of EET pathways. The application prospects of biogenic nanomaterials are then highlighted in multiple fields of (bio-) energy conversion, remediation of organic pollutants and toxic metals, and biomedicine. A summary and outlook are given with discussion on challenges of bio-manufacturing with well-defined controllability.
\end{abstract}

Keywords: Extracellular electron transfer, Biosynthesis, Inorganic nanomaterials, Microbial nano-factory, Metal nanoparticles

\section{Introduction}

Nanostructured materials having at least one of their dimension sizes smaller than $100 \mathrm{~nm}$ have demonstrated wide applicability in producing industrial products and daily necessities. The fabrication and utilization

*Correspondence: sallyyunhong@jxnu.edu.cn

Nanchang Key Laboratory of Microbial Resources Exploitation \& Utilization From Poyang Lake Wetland, College of Life Sciences, Jiangxi Normal University, Nanchang 330022, China of nanomaterials have thus sparked widespread interest from both academia and industries. One such important class of nanomaterials that have allured global researchers is metal nanoparticles (MNPs), which have become crucial components in multiple cutting-edge areas including catalysis, sensors, clinical diagnosis, nanomedicine, antimicrobial agents, environmental remediation and agriculture [1-4].

Two categories of nanofabrication technologies are known as top-down and bottom-up approaches [5]. For

c) The Author(s) 2021. This article is licensed under a Creative Commons Attribution 4.0 International License, which permits use, sharing, adaptation, distribution and reproduction in any medium or format, as long as you give appropriate credit to the original author(s) and the source, provide a link to the Creative Commons licence, and indicate if changes were made. The images or other third party material in this article are included in the article's Creative Commons licence, unless indicated otherwise in a credit line to the material. If material is not included in the article's Creative Commons licence and your intended use is not permitted by statutory regulation or exceeds the permitted use, you will need to obtain permission directly from the copyright holder. To view a copy of this licence, visit http://creativeco mmons.org/licenses/by/4.0/. The Creative Commons Public Domain Dedication waiver (http://creativecommons.org/publicdomain/ zero/1.0/) applies to the data made available in this article, unless otherwise stated in a credit line to the data. 
the former, nanosized materials are prepared through the rupture of bulk materials to fine particles, and such a process is usually conducted by diverse physical and mechanical techniques like lithography, laser ablation, sputtering, ball milling and arc-discharging $[6,7]$. These techniques themselves are simple, and nanosized materials can be produced quickly after relatively short technological process, but expensive specialized equipment and high energy consumption are usually inevitable. Meanwhile, a variety of efficient chemical bottom-up methods, where atoms assemble into nuclei and then form nanoparticles, have been intensively studied to synthesize and modulate nanomaterials with specific shape and size [8].

Indeed, chemical methodologies, including but not limited to, aqueous reaction using chemical reducing agents (e.g. hydrazine hydrate and sodium borohydride), electrochemical deposition, hydrothermal/solvothermal synthesis, sol-gel processing, chemical liquid/vapor deposition, have been developed up to now $[5,6]$. These approaches can not only produce diverse nanomaterials with fairly high yields, but also endow fine controllability in tailoring nanostructures and properties of the products. Nevertheless, they have been encountering some serious challenges of harsh reaction conditions (e.g. $\mathrm{pH}$ and temperature), potential risks in human health and environment, and low cost-effectiveness. Moreover, there are biosafety concerns on products synthesized chemically using hazardous reagents, which restricts their applications in many areas, particularly in medicines and pharmaceuticals [9].

Impressively, biological methodology is becoming a favourite in nanomaterial synthesis nowadays to address challenges in chemical synthesis. Compared to chemical routes, biosynthesis using natural and biological materials as reducing, stabilizing and capping agents are simple, energy- and cost-effective, mild and environment-friendly, which is termed as "Green Chemistry" $[2,6]$. More significantly, the biologically synthesized nanomaterials have much better competitiveness in biocompatibility, compared to those chemically derived counterparts. On the one hand, the biogenic nanomaterials are free from toxic contamination of by-products that are usually involved in chemical synthesis process; on the other hand, the biosynthesis do not need additional stabilizing agents because either the used organisms themselves or their constituents can act as capping and stabilizing agents and the attached biological components in turn form biocompatible envelopes on the resultant nanomaterials, leading to actively interact with biological systems [2]. As one of the most abundant biological resources, some microorganisms have adapted to habitat contaminated with toxic metals, and thus evolved powerful tactics for remediating polluted environment while recycling metal resources $[7,10]$, and some review articles on the biosynthesis of MNPs using diverse microorganisms including bacteria, yeast, fungi, alga, etc. and their applications have been published in recent years $[1$, $2,6,7,10]$.

Nevertheless, our particular concern is dissimilatory metal-reducing bacteria (DMRB) like Shewanella and Geobacter species that are capable of peculiar extracellular electron transfer (EET). Due to their unique functions on electron exchange with extracellular environments, DMRB have aroused intensive research enthusiasm over the past two decades, not only on uncovering their ecological distributions and functions in nature but also on developing a series of novel technological systems in many interdisciplinary areas such as biogeochemistry, bioelectrochemistry, environmental science \& engineering, and nanobiotechnology [11-14]. In absence of electron acceptors that are available intracellularly (e.g. oxygen and soluble molecules with high oxidation states), these bacteria can also anaerobically oxidize organic matters inside cells, and then transfer electrons released across their cell envelope barriers to extracellular redoxactive minerals (electron acceptors), such as those that contain iron $\left(\mathrm{Fe}^{2+}\right.$ and/or $\left.\mathrm{Fe}^{3+}\right)$ and manganese $\left(\mathrm{Mn}^{3+}\right.$ or $\mathrm{Mn}^{4+}$ ), to drive the biogeochemical cycling of elements [15-18]. They also can use solid electrodes like graphite as terminal electron acceptors, thereby coupling bacterial intracellular energy metabolism with bioelectricity production, and such a system is referred to as microbial fuel cell [13]. These bacteria possessing EET ability are generally termed as electroactive microorganisms, and G. sulfurreducens and S. oneidensis MR-1 are the two most important model strains [19]. More impressively, many strains of DMRB have functions on the biosynthesis and bioassembly of nano-sized materials associated with their versatile EET features, especially MNPs. With great advances in elucidating bacterial EET mechanisms over the last decade, many noble metal nanoparticles [20-24], their alloys $[25,26]$, metal oxides $[27,28]$ and chalcogenides $[29,30]$ have been synthesized by Shewanella and Geobacter species. Besides, the bacterial EET pathway that pumps electrons out of the cells enables the extracellular reduction of metal ions to form MNPs in the culture, which is beneficial to their subsequent separation and purification. The biogenic metal nanomaterials are promising in many application fields (Fig. 1).

Shewanella and Geobacter species are able to produce graphene through the biological reduction of graphene oxide (GO), a two-dimensional honeycomb-structured single atom layer carbon material with high hydrophilicity and biocompatibility. More interestingly, bacterial EET-driven biosynthesis provokes an interesting tactics of the self-assembling bio-abiotic hybrid composed 


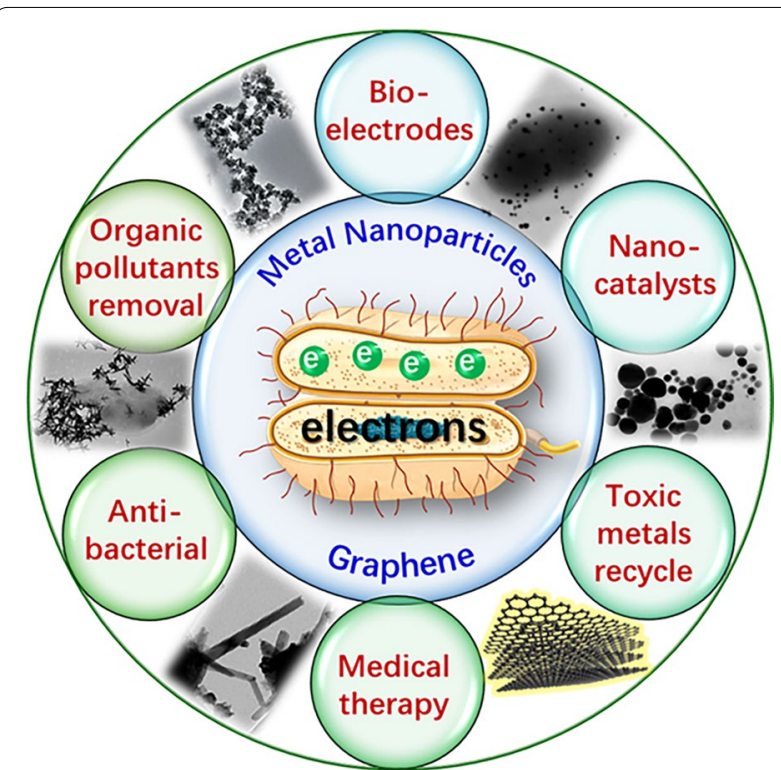

Fig. 1 Overview for biogenic nanostructured materials (metal nanoparticles and graphene) and their diverse applications

of bacterial cell and inorganic nanomaterials, which exhibit many novel properties originated from their intimate interractions, leading to broader applications. [31-34] Moreover, with the innovation and development of various biotechnologies represented by synthetic biology, the controllable biosynthesis of nanomaterials with well-defined structures and features by virtue of rationally tailoring the EET pathway becomes feasible.

Taking into consideration of an ever-growing research enthusiasm and great achievement, a critical review focusing especially on the biosynthesis of nanomaterials inspired by bacterial EET is needed.

\section{Bacterial extracellular electron transfer}

The earliest observation of microbial capacity to exchange electrons with extracellular environments was observed by Potter in the early 1900s [35], while the research upsurge started after the discoveries of two typical DMRB (Shewanella and Geobacter spp.) three decades ago $[15,17]$. Since then, extensive studies have devoted to molecular mechanisms by which DMRB cells exchange electrons with extracellular redox-active substances, particularlly solid electrodes and inorganic minerals, as well as their functions on the earth's ecology and geochemical element cycle [11]. Meanwhile, a series of microbial electrochemical technologies, such as microbial fuel cell, microbial electrolysis cells, microbial desalination cell and microbial electrosynthesis, have also emerged on the basis of electron exchange between electroactive microorganisms and solid electrodes [13,36].

As shown in Fig. 2, the bacterial EET process can carry out either directly or indirectly $[11,13,36]$. For the model strain of $S$. oneidensis MR-1, its direct EET relies on a metal-reducing (Mtr) conduit consisting of six multiheme $c$-type cytochromes (c-Cyts): CymA, $\mathrm{Fcc}_{3}$, MtrA, $\mathrm{MtrC}$, OmcA and small tetraheme cytochrome (STC), and a porin-like MtrB located on the outer-membrane, which work together for electron trans-membrane transport [11]. In detail, CymA oxidizes the menaquinol pool located in the cytoplasmic membrane wherein the electrons come from reducing equivalents produced during intracellular energy metabolism, and transfers electrons to the periplasmic redox proteins $\mathrm{Fcc}_{3}$ and STC. Proteins MtrA, MtrB and MtrC form a ternary complex across the
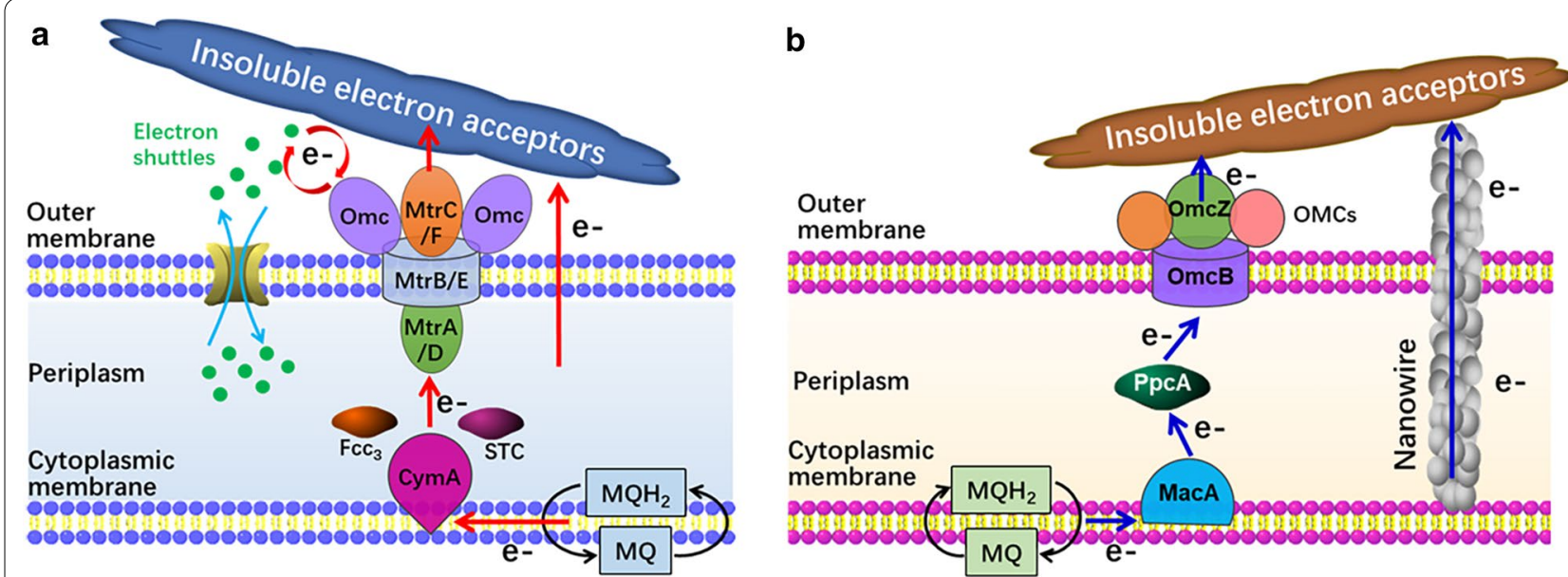

Fig. 2 Mechanistic diagram for the bacterial EET. a Shewanella oneidensis MR-1, and b Geobacter sulfurreducens 
outer-membrane responsible for transporting electrons from the periplasmic space to bacterial cell surface [3740]. Then MtrC and OmcA can interact with each other and deliver electrons to extracellular electron acceptors (e.g. solid electrodes and insoluble minerals) directly contacted with bacterial surfaces [41-44]. Notably, the direct physical contact between extracellular electron acceptors and bacterial out-membrane $c$-Cyts (MtrC and OmcA) is necessary for this EET mode. The Mtr pathway of $S$. oneidensis MR-1 is the best-characterized EET route so far, and its homologues are found in all sequenced Shewanella species $[11,45]$. In the case of indirect pattern, S. oneidensis MR-1 secretes small redox-active molecules such as flavins or other quinones to execute electron shuttling back and forth between cells and external electron acceptors $[46,47]$. The indirect EET mode relies on the abilities of these endogenous electron shuttles to effectively pass through the cell membrane barrier. However, the two EET pathways seem to be not independent. For instance, out-membrane $c$-Cyts have been evidenced to serve as terminal reductases for the extracellular reduction of electron shuttles [45, 48]. Besides, some studies have demonstrated that the flavins can act as the co-factors for outer-membrane MtrC and OmcA to accelerate interfacial electron transfer rate $[49,50]$.

Multiheme $c$-Cyts, especially diverse types of Omc proteins, are also identified to play key roles in the EET process of G. sulfurreducens, and these $c$-Cyts work collectively to transfer electrons from the quinol pool existed in the cytoplasmic membrane, across the periplasm and outer membrane to the bacterial outside $[11,51,52]$. For example, the deletion of OmcZ (an out-membrane $c$-Cyts of G. sulfurreducens) resulted in alomost failure in EET capacity [53, 54]. Moreover, it should be pointed out that G. sulfurreducens can generate specific conductive pili that are referred to as bacterial nanowires with metal-like conductivity. The bio-nanowires serve as an alternative direct pathway to achieve more effective electron transport especially in biofilms [55, 56].

There are convincible evidences to indicate that extracellular polymeric substances (EPS), a complex biopolymer mixture produced by bacterial cells, are involved in the EET process [57]. For example, about 20 redox proteins including $c$-Cyts of $\mathrm{MtrC}$ and OmcA were detected in EPS from Shewanella sp. HRCR-1 biofilms [58]. Moreover, EPS matrices extracted from S. oneidensis MR-1 have been confirmed to be electrochemically active with the clear observation of redox peaks of $c$-Cyts by voltammetry measurement $[59,60]$. On account of the existence of vast functional groups like carboxyl, phosphoric, amine and hydroxyl groups, the EPS matrices are expected to be relevant to the formation of MNPs because of their electrostatic affinity for metal ions.

For more details about mechanisms underlying EET, refer to some previous reviews [11-13, 19, 36].

\section{Biosynthesis of metal nanoparticles}

The versatile and vigorous EET features of Shewanella and Geobacter species not only enable them to output electrons for extracellular reduction of redox-active minerals and electrodes, but also inspire a promising function on the bio-manufacturing of nanomaterials especially MNPs when using different metal ions as electron acceptors. Some inorganic nanoparticles are naturally presented in microorganisms such as magnetosome particles in magnetotactic bacteria [61]. The biological mineralization or/and reduction of hydrosoluble metal ions to form low-bioavailable solid-phase particles are inherent behaviors for many bacteria, by which they can get rid of the potential toxicity and stress effect caused by metal ions. In comparison to intracellular biosynthesis, bacteria possessing EET characteristic can generate MNPs outside cells or/and on the surface of cells via the reduction process driven by the transfer of extracellular electrons without the need of intracellular uptake of metal ions. Clearly the EET route endows the bacteria with a flexible prevention strategy to lower the risk of toxic metal ions, and thereby holds a promising prospect in biosynthesis, even the recovery of MNPs.

\section{Monometallic nanoparticle}

The intracellular reducing equivalents including NADH and NADPH produced by the oxidative metabolism of organic substrates are primary forces to drive the bioreduction reaction. Metal ions, including $\mathrm{Au}^{3+}, \mathrm{Ag}^{+}, \mathrm{Pd}^{2+}$, $\mathrm{Se}^{4+}, \mathrm{Te}^{4+}$ and $\mathrm{Cu}^{2+}$ with much higher redox potentials than NADH and NADPH $\left(E^{0} \approx-0.32 \mathrm{~V}\right)$ [62], can be effectively reduced in theory to insoluble elemental metals inside cells as well as at extracellular matrix once the reducing forces are accessible through the EET pathways (Fig. 3). Noble metal nanoparticles are valuable materials with various applications such as in catalysis and medical sensing and diagnosis $[63,64]$. The concept of green chemistry has spawned intensive research on the biosynthesis and recovery of noble MNPs [65]. On the other hand, other monometallic nanoparticles such as nanostructured chalcogen metalloids and copper nanoparticles have also been developed.

\section{Gold nanoparticles}

As a pioneering work, Suresh and co-workers reported the bio-fabrication of gold nanoparticles (Au-NPs) using S. oneidensis MR-1 cells as biological factories, which demonstrated the substantial ability of $S$. oneidensis 


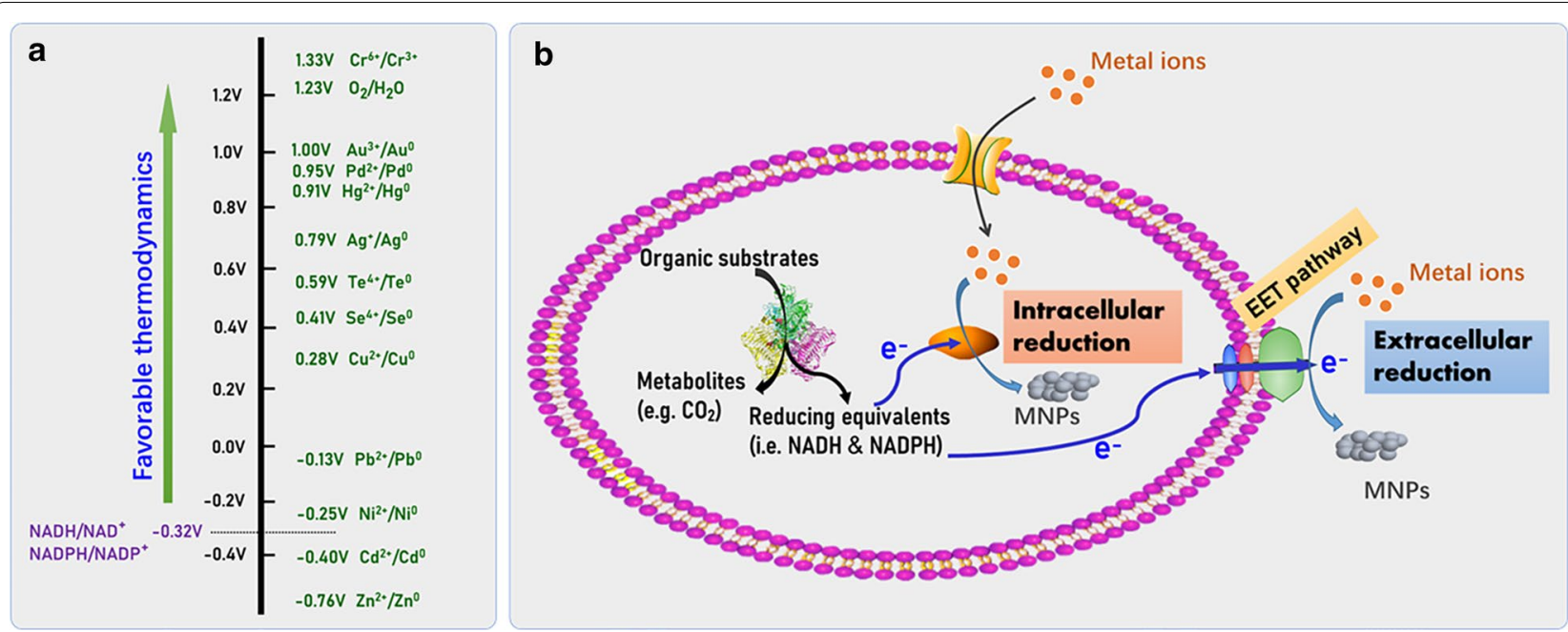

Fig. 3 Illustration of the thermodynamic feasibility for microbial reduction of metal ions to elemental forms under anaerobic condition (a), and the biosynthesis of MNPs through microbial reduction of metal ions both inside and outside cells (b)

MR-1 in the extracellular reduction of chloroaurate $\left(\mathrm{Au}^{3+}\right)$, producing discrete spherical Au-NPs outside the cells with an average size of $12 \pm 5 \mathrm{~nm}$ [20]. The biosynthesized Au-NPs were hydrophilic and not aggregated even after several months, and exhibited high biocompatibility with neither toxicity nor inhibition to both Gram-positive and Gram-negative bacteria, because they were likely capped by a detachable protein/peptide coat during the formation process. To reveal the contribution of the bacterial surface structure on Au-NPs production, Ishiki and co-workers tracked the bioformation process of Au-NPs on S. oneidensis MR-1 cell surface by using electron microscopy, zeta potential and spectrometry analyses [66]. The authors found that both the extracellular electron transport and the secretion of extracellular polysaccharide (EPS) executed the $\mathrm{Au}^{3+}$ reduction and controlled characteristics of the produced Au-NPs such as their particle size.

Interestingly, the mutant of S. oneidensis MR-1 lacking proteins MtrC and OmcA, two important outer-membrane $c$-Cyts for direct EET, still could synthesize Au-NPs on the bacterial cell surface. Moreover, the biosynthesized $\mathrm{Au}-\mathrm{NPs}$ grown on the cell surface were found to repair the damaged EET chain of the mutant strain to a certain degree [67]. These findings signify the possible existence of alternative routes responsible for the reductive synthesis of Au-NPs in addition to the Mtr pathway. Likewise, the ability in biological synthesis of Au-NPs has been observed later for other Shewanella species including S. putrefaciens CN32 [68], S. haliotis [69] and Shewanella sp. CNZ-1 [70]. The size distributions of Au-NPs were dependent on various reaction conditions including bacterial biomass loading, concentrations of electron donors and gold ions, $\mathrm{pH}$ environment, etc.

In contrast to Shewanella, Geobacter species can construct a thick and dense biofilm matrix when grown on an electrode surface [71]. The well-reductive biofilm matrix with high availability of electrons is expected to reduce gold ions to Au-NPs, and biomolecules in the biofilm matrix can serve as active sites for the nucleation and stabilization of Au-NPs [72]. Inspiringly, Tanzil and co-workers made an attempt to synthesize Au-NPs using an electrode-respiring G. sulfurreducens biofilm, and AuNPs with an average size of $20 \mathrm{~nm}$ were formed inside the extracellular matrix of the biofilm [24]. The in-situ bio-formation of Au-NPs was also realized in another $G$. sulfurreducens-electrode biofilm by the slow addition of $\mathrm{NaAuCl}_{4}$ precursors during its development [73]. These achievements demonstrates the potential tactics for constructing Au-NPs hybridized electroactive biofilms, and collaboration between inorganic nanoparticles and biomacromolecules is worth looking forward to.

\section{Silver nanoparticles}

Silver nanoparticles (Ag-NPs) have showed their applications in over 200 products including antimicrobial coatings, medical devices, molecular diagnostics, sensors, electronics and fillers [74], making biological methodologies for Ag-NPs synthesis attractive. The extracellular biosynthesis of silver-based single nanocrystallites of well-defined composition and homogeneous morphology has been observed when S. oneidensis MR-1 cells were inoculated in aqueous silver nitrate solution [21]. The produced biogenic Ag-NPs with monodispersed nanospheres ranging from 2 to $11 \mathrm{~nm}$ showed higher 
toxicity towards both Gram-positive (Bacillus subtilis) and Gram-negative (Escherichia coli and S. oneidensis) bacteria compared to those chemically synthesized counterparts. Specifically, the reduction of $\mathrm{Ag}^{+}$to form $\mathrm{Ag}-$ NPs was also achieved by using the EPS extracted from $S$. oneidensis, and $c$-Cyts present in the EPS matrix contributed to the biological reduction [75]. However the EPSenabled reduction process is usually compromised by the relatively low reducing rate, because the reducing capability of EPS lacking constant energy supply from bacterial cells is always weak. To address such a challenge, a light-induced tactic was developed, where the reduction of $\mathrm{Ag}^{+}$by EPS from S. oneidensis MR-1 was accelerated significantly by illumination treatment under both visible and UV light [76]. Besides, the outer membrane $c$-Cyts of $S$. oneidensis MR-1 exhibited a significant effect on the size and activity of extracellularly synthesized Ag-NPs, and the lack of MtrC and OmcA reduced the particle size, but increased the antibacterial activity of the biogenic Ag-NPs [77].

\section{Palladium nanoparticles}

Palladium (Pd) is attracted ever-increasing interest in both scientific and industrial communities due to its similar high activity in various catalytic reactions but much higher earth reserves compared to platinum (Pt) [78].

Shewanella and Geobacter species have been widely used to synthesize Pd-NPs due to their dissimilatory reduction properties. Besides, they also provide an alternative approach to recycle Pd resources from wastewater. S. oneidensis MR-1 can reduce soluble $\mathrm{Pd}^{2+}$, and thus precipitate Pd-NPs either on the cell wall or inside the periplasmic space in the presence of electron donors such as hydrogen gas, formate, lactate, pyruvate and ethanol [79]. Moreover, the size distribution and catalytic reactivity of Pd-NPs produced by S. oneidensis MR-1 could be tailored by changing electron donors or controlling the ratio of precursor ions to the bacterial cells [80]. The functions of the EET components of S. oneidensis MR-1, including outer-membrane $\mathrm{MtrC}$ and electron shuttles such as flavins, on the Pd-NPs biosynthesis were elaborated recently by Dundas and co-workers, and with the variation of the EET components, observable changes in the rate of their biosynthesis, size distribution and cellular localization were observed (Fig. 4) [81]. They also found that $\mathrm{MtrC}$ was a critical machine for delivering electrons to $\mathrm{Pd}^{2+}$ and mediating Pd-NPs nucleation, and the particle size decreased in a dose-dependent manner with the increase in flavin concentration, but the particle number per cell increased. These findings provide substantial evidences for the concept that bacterial EET coordinates the biological formation of inorganic nanoparticles. Given their genetic tractability, Shewanella spp. are expected to be developed as a model platform for tracing nanoparticle biogenesis and engineering functional nanoparticles for emerging applications.

The ability of G. sulfurreducens PCA to reduce $\mathrm{Pd}^{2+}$ using acetate as electron donors at neutral $\mathrm{pH}$ and physiological temperature was firstly documented by PatEspadas and co-workers [82]. The authors found that the productivity of Pd-NPs was greatly enhanced after the addition of redox mediator (anthraquinone-2,6-disulfonate, AQDS). In addition to the Pd-NPs on the bacterial surface, others detached from the cells were also observed, probably owing to that the $\mathrm{Pd}^{2+}$ around the bacterial cells accepted electrons by AQDS mediators rather than directly from membrane-bound $c$-Cyts [83]. The production of Pd-NPs outside the cells has also been demonstrated in another research with $G$. sulfurreducens PCA [23]. Given that these extracellular nanoparticles can be easily extracted from bacterial cultures through simple centrifugation, the extracellular biosynthesis is greatly beneficial to industrial production. Very recently, the global transcriptional analysis of G. sulfurreducens PCA revealed the crucial role of electrically conductive pili in $\mathrm{Pd}^{2+}$ reduction [84], but more investigations are needed to elaborate the underlying mechanism. Meanwhile, the expression levels of $c$-Cyts during $\mathrm{Pd}^{2+}$ reduction were found to be distinctly different to that when either $\mathrm{Fe}^{3+}$ or electrode was used as electron acceptors [84], which further implies the complicated and changeable mechanism underlying the bacterial extracellular reduction process.

\section{Nanostructured chalcogen metalloids}

Elemental selenium (Se) and tellurium ( $\mathrm{Te}$ ) that belong to chalcogen metalloids with unique $p$-type semiconductor characteristics have applications in electronic, photoelectronic and optic products, glasses, pigments and sensors [85]. Both of them have a wide range of chemical valence states from -2 to +4 , and exist in several different forms, including soluble oxyanions $\left(\mathrm{SeO}_{4}{ }^{2-}, \mathrm{SeO}_{3}{ }^{2-}\right.$, $\left.\mathrm{TeO}_{4}{ }^{2-}, \mathrm{TeO}_{3}{ }^{2-}\right)$, insoluble elemental states $\left(\mathrm{Se}^{0}, \mathrm{Te}^{0}\right)$ and inorganic chalcogenides $\left(\mathrm{Se}^{2-}, \mathrm{Te}^{2-}\right)$, depending on prevailing redox conditions. Bacteria play a key role in their biogeochemical cycles [85]. As early as in 2005, S. oneidensis MR-1 was reported to reduce selenite $\left(\mathrm{SeO}_{3}{ }^{2-}\right)$ and tellurite $\left(\mathrm{TeO}_{3}{ }^{2-}\right)$ under anaerobic conditions to produce nanosized $\mathrm{Se}^{0}$ and $\mathrm{Te}^{0}$ deposits [86]. Since then, many Shewanella strains have been documented with biosynthetic abilities of zero-valent Se nanoparticles (Se-NPs) and Te nanoparticles (Te-NPs) from oxyanions [87-97].

The periplasmic fumarate reductase FccA of S. oneidensis MR-1 has been identified to reduce selenite during the 


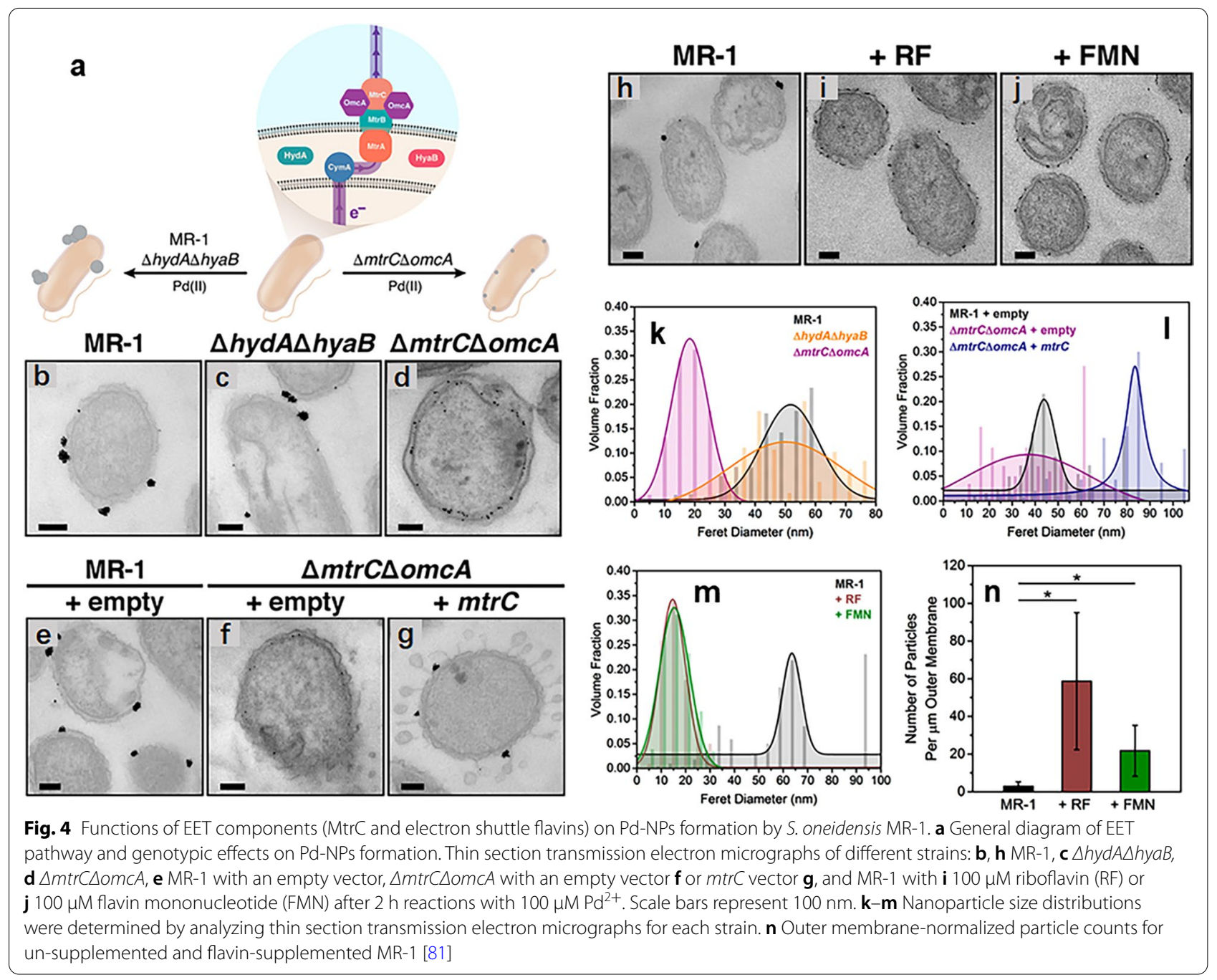

bio-formation of zero-valent Se-NPs [87]. Impressively, the selenite reduction process in S. oneidensis MR-1 cells could be well tuned by electron shuttles such as AQDS and riboflavin. The addition of these electron shuttles not only accelerated markedly the selenite reduction rate but also diverted the location of Se-NPs from inside to outside cells [88]. Moreover, the shape, size distribution and formation rate of Se-NPs could be effectively tuned by multiple biosynthetic reaction conditions, including bacterial biomass, selenite concentration, dissolved oxygen, incubation temperature and reaction time [89, 97]. For example, Shewanella sp. HN-41 produced well-shaped spherical Se-NPs under either anaerobic or hypoxic conditions, while irregular-shaped products with smaller sizes were developed under oxygen-saturated conditions [89]. The biomass density of Shewanella sp. HN-41 and selenite concentration also impacted the selenite reduction rate and the particle size distribution and productivity of Se-NPs [97]. More impressively, the spherical
Se-NPs produced by Shewanella sp. HN-41 were found to be rapidly transformed into nanowires (1-D structure) or/and nanoribbons (2-D structure) after being transferred from the aqueous phase to the dimethyl sulfoxide (DMSO) solution [90]. The crystallinities and shapes of Se-NPs depended on the DMSO concentration. These findings hint a possible solution for the controllable production of Se-NPs with shape-dependent functions.

S. oneidensis MR-1 could also reduce tellurite to elemental tellurium under an anaerobic condition, thereby leading to the intracellular accumulation of needleshaped crystalline Te nanorods [93]. Interestingly, the tellurite reduction rate of $S$. oneidensis MR-1was promoted distinctly in the presence of $\mathrm{Fe}^{3+}$ acting as a co-existing electron acceptor [94]. More surprisingly, only extracellular crystalline Te nanorods with the length of $240 \mathrm{~nm}$ and width of $25 \mathrm{~nm}$ were observed after the addition of $\mathrm{Fe}^{3+}$. The extracellular formation of tellurite complex precipitates triggered by the biological production of $\mathrm{Fe}^{2+}$ from 
$\mathrm{Fe}^{3+}$ under the anaerobic condition was suggested to be responsible for the exclusive formation of the extracellular products, through which these generated precipitates were reduced into Te nanorods by $S$. oneidensis MR-1 extracellular respiration [94, 98]. Except for S. oneidensis MR-1, the strains of S. baltica GUSDZ9[96] and Shewanella sp. Taa[91] were also documented to produce $\mathrm{Te}$ nanorods and globular particles, respectively. Therefore, Shewanella species can achieve dual merits of detoxifying harmful tellurite and synchronously recycling industry-applicable Te resources.

Biosynthesis of Se- and Te-NPs has also been documented with G. sulfurreducens. $[95,99,100]$ G. sulfurreducens has been proved to reduce $\mathrm{Se}^{4+}$ to produce $\mathrm{Se}$ nanospheres using both acetate and hydrogen as electron donors, and the reduction rate depended on the used electron donors as well as whether or not addition of redox mediators, but a fraction of Se elements was reduced further to $\mathrm{Se}^{2-}$ because of the instability of $\mathrm{Se}^{0}$. [95] Jahan et al. found that a porin-like protein ExtI from G. sulfurreducens participated the reduction of selenite and tellurite because the extI deficiency caused an obvious decrease in the reduction ability [99]. Therefore, ExtI was hypothesized to play a role not only in selenite uptake but also in Se-NPs formation/excretion [100]. Nevertheless, the bio-formation mechanism of Se- and Te-NPs is still unclear, and further in-depth research is needed.

\section{Copper nanoparticles}

Given its high natural abundance and relatively low cost, the applications of copper $(\mathrm{Cu})$ and $\mathrm{Cu}$-based NPs in catalysis and antibacterial products have always generated interest [101, 102]. S. oneidensis MR-1 can directly reduce $\mathrm{Cu}^{2+}$ to its elemental form in the absence of oxygen. In a study case, nanostructured $\mathrm{Cu}$ precipitates (20$50 \mathrm{~nm}$ ) were formed inside the cells when S. oneidensis MR-1 were incubated anaerobically in $0.05 \mathrm{mM} \mathrm{CuSO}_{4}$ solution with the addition of lactate as the electron donor [103]. Meanwhile, there were also a small amount of large-sized aggregates over $200 \mathrm{~nm}$ observed in the extracellular matrix. However, a research on biosynthesis of Cu-NPs using S. loihica PV-4 exhibited inconsistent results, where there were abundant small-sized $\mathrm{Cu}-\mathrm{NPs}$ $(10-16 \mathrm{~nm})$ on the bacterial cell surface while a little bit of intracellular precipitates [104]. Very recently, highcrystallizd $\mathrm{Cu}$-NPs with a small diameter ranging from 4 to $10 \mathrm{~nm}$ were grafted on carbon nanotube (CNT) surfaces through a biosynthetic approach using $S$. oneidensis MR-1, which further proves the ability of Shewanella spp. in extracellular $\mathrm{Cu}^{2+}$ reduction [105].

\section{Bimetallic nanoparticles}

Integration of two kinds of metals into single bimetallic nanoparticles often leads to more unique and superior physicochemical properties than their monometallic counterparts [106]. Synthesis of bimetallic nanoparticles is therefore receiving attention. For instance, bimetallic Pd-Au nanoparticles have been applied as excellent catalysts for different reactions, including but not limited to carbon dioxide reduction [107], oxygen reduction reaction [108], methanol oxidation [109], nitrite reduction [110], and selective detection of reactive oxygen and nitrogen species [111]. Great effort has been placed on developing physical and chemical methodologies capable of synthesizing bimetallic nanocrystals with welldefined structures and rational-tuned features [106]. Nevertheless, how to fabricate functional bimetallic nanoparticles by a more facile and green approach encourages researchers to develop an alternative protocol from microbial perspective [112].

As what elaborated before, various kind of monometallic nanoparticles especially noble metals can be biosynthesized easily by bacteria possessing the EET ability. Accordingly, S. oneidensis MR-1 has been inspired to biosynthesize Pd-NPs and Au-NPs on bacterial cell surfaces. The OmcA/MtrC complex was proved experimentally to work as a key machine in the bioreduction of $\mathrm{Pd}^{2+}$ and $\mathrm{Au}^{3+}$, indicating the crucial role of the direct electron transfer endowed by out-membrane $c$-Cyts in the biosynthetic process of noble nanoparticles, and intriguingly, the biosynthesized Pd-NPs and Au-NPs that were separated from each other could fuse together after a facile hydrothermal reaction, thereby becoming $\mathrm{Pd} / \mathrm{Au}$ alloys with outstanding electrocatalytic activity [25]. This work presents a feasible case of green biosynthesis of functional bimetallic nanoparticles. More impressively, S. oneidensis MR-1 was found recently to be capable of directly producing biogenic Pd/Pt-NPs when incubated in the solution of $\mathrm{Pd}^{2+}$ and $\mathrm{Pt}^{4+}$ at two independent laboratories $[26,113]$. The produced bimetallic $\mathrm{Pd} / \mathrm{Pt}$ NPs exhibited much superior catalytic activity towards organic pollutants (e.g. 4-nitrophenol) compared to the monometallic counterparts (Pd-NPs and Pt-NPs). Additionaly, electron shuttles such as AQDS were demonstrated to not only promote the reduction efficiency of $\mathrm{Pd}^{2+}$ or/and $\mathrm{Pt}^{4+}$ but also lower the sizes of both monoand bi-metallic nanoparticles [26]. Although only a few of literatures about the biosynthesis of bimetallic nanoparticles, we believe that much more research activities in this direction are look forward to in the future because of their extraordinary characteristics and promising applications. 


\section{Magnetite nanoparticles}

Some DMRB can respire a broad range of high oxidation state minerals such as $\mathrm{Fe}^{3+}$-oxyhydroxides, so as to take part in their biogeochemical cycles [11, 114]. Such a natural biotransformation process offers a practical solution to the production of functional mineral-derived nanomaterials. Magnetite $\left(\mathrm{Fe}_{3} \mathrm{O}_{4}\right)$ nanoparticles have been particularly highlighted in terms of their fruitful applications in cancer therapy, drug delivery, chemical and biological sensors, magnetic catalysts, magnetic data storage and environmental remediation, due to their specific magnetic properties and high surface reactivities in nanoscales [115-118].

Magnetotactic bacteria naturally produce intracellular magnetite nanoparticles (magnetosomes) with high purity and crystallinity, uniform morphology and grainsize distribution [61]. In contrast to the intracellular biomineralization of magnetotactic bacteria, the DMRB tend to produce extracellular magnetite nanoparticles by the dissimilatory reduction approach outside cells, which can bring great convenience to product recovery. Many iron-reducing bacteria including S. oneidensis MR-1 [119, 120], Shewanella sp. HN-41 [121, 122], S. piezotolerans WP3[123] and G. sulfurreducens[124-132] have been exploited to produce well-defined magnetite nanoparticles through the dissimilatory reduction of poorly crystalline $\mathrm{Fe}^{3+}$-oxyhydroxides. Besides, the biosynthesized magnetite nanoparticles could well support nanostructured Pd for significent improvement on functionality and applicability $[125,133]$.

What should be noted is that, the biosynthetic processes are tunable and scalable with respect to particle size, surface reactivity, and magnetic, optical and thermal properties. The types of bacteria and organic substrates as electron donors, as well as the density of bacterial biomass, mineral precursors and redox mediators have been demonstrated to be of great significance to the products $[119,120,122,126]$. It is well known that hetero-atom doping can tune the structure and property of nanomaterials. The biological incorporation of $\mathrm{Co}^{2+}$ and $\mathrm{Zn}^{2+}$ into the structure of magnetite nanoparticles has been realized using G. sulfurreducens, and the produced Co and $\mathrm{Zn}$-doped nanoparticles showed enhanced magnetic properties dependent on the hetero-atom doping level $[127,128,132]$. Although the production of biomagnetite nanoparticles by iron-reducing bacteria has yet to be taken up in industry, an attempt on scale-up production from laboratory- to pilot plant- scale has been carried out [129]. In this trial, no significant impact was observed on the nanoparticle size, magnetic property and surface reactivity of the products during the scaleup from $10 \mathrm{~mL}$ to $10 \mathrm{~L}$. Besides, the formation of other iron mineral nanomaterials such as siderite $\left(\mathrm{FeCO}_{3}\right)$ nanoparticles and goethite $(\alpha-\mathrm{FeOOH})$ nanowires has been also observed in iron-reducing bacterial cultures containing $\mathrm{Fe}^{3+}$-oxyhydroxides $[27,122]$.

\section{Metal chalcogenide nanoparticles}

Metal chalcogenides are emerging as promising nanomaterials due to their unique size- and shape-tunable optoelectronic, physicochemical and biological properties. Considerable interest on innovations of methodologies for controllable synthesis of them has been raised among academic and scientific communities. The biological synthetic route with benefits of low energy consumption and less impact on environment is beyond all doubt highly preferred nowadays [134, 135].

Shewanella spp. are capable of using thiosulfate, tetrathionate, sulfite and elemental sulfur as terminal electron acceptors for anaerobic respiration, and consequently produce $\mathrm{S}^{2-}$ that has high affinity towards a variety of metal ions to form metal sulphides [136-139]. Lee et al. reported a pioneering work on the biosynthesis of an extracellular network of filamentous arsenicsulfide (As-S) nanotubes (20-100 $\mathrm{nm}$ in width and up to $30 \mu \mathrm{m}$ in length) by Shewanella sp. HN-41 under anaerobic conditions, in which the transformation process was triggered by the biological reduction of $\mathrm{As}^{5+}$ and thiosulfate [29]. The produced yellow As-S filamentous nanotubes behaved as both electrical conductivity of metals and photoconductive characteristics of semiconductors, indicating their promising applications in nano- and opto-electronic devices. Whereafter, various ternary and quaternary chalcogenides including As-S-Se, As-Cd-S and As-Cd-S-Se nanotubes were synthesized using the above-mentioned As-S nanotubes as templates through microbiological or/and abiotic modifications under ambient conditions [140]. Impressively, the biosynthesized $\mathrm{As}_{4} \mathrm{~S}_{4}$ has been successfully adopted as Li-ion active electrode materials after its low conductivity was effectively improved through the introduction of high-conductive graphene [141]. Strain of Shewanella sp. ANA-3 was reported to rapidly synthesize extracellular $\mathrm{As}_{2} \mathrm{~S}_{3}$ nanofibers with a high yield (504 mg per liter of the culture, $82 \%$ of the maximum theoretical value) through anaerobical reduction of $\mathrm{As}^{5+}$ and thiosulfate [142].

It has been widely demonstrated that the biological production of iron sulfides can occur as a consequence of dissimilatory reduction of diverse ferric iron $\left(\mathrm{Fe}^{3+}\right)$ by Shewanella spp., including both dissolved ions and insoluble minerals when they coexist with thiosulfate, sulfite or/and elemental sulfur [143-148]. To our best knowledge, S. oneidensis MR-1 [144, 147, 148], S. loihica PV-4[143] and S. putrefaciens CN32[146] have been documented capable of biosynthesizing nanostructured FeS under anaerobic conditions. The structure, 
size and reactive activity of these biogenic FeS are, to a great extent, dependent on the synthesis conditions. Very recently, Yu et al. investigated the effect of biogenic $\mathrm{S}^{2-}$ release rate that could be controlled by the initial thiosulfate dosage on the particle size distribution of FeS-NPs, and found that the $\mathrm{Fe}^{3+}$ was mainly reduced by the $S$. oneidensis $\mathrm{MR}$-1-produced $\mathrm{S}^{2-}$ rather than the cells themselves once the initial thiosulfate concentration exceeded $5 \mathrm{mM}$ [148]. More importantly, the authors also revealed that the biogenic $\mathrm{S}^{2-}$ release rate not only altered the $\mathrm{Fe}^{3+}$ reduction manner but also tuned the particle size of FeS products that showed a clear tendency to increase with increasing the biogenic $\mathrm{S}^{2-}$ release rate. This work shows a new strategy to realize the controllable synthesis of biogenic nanoparticles. In another interesting work, $\mathrm{Fe}^{2+}$ released from the metal-complex dye naphthol green B through biodegradation by $S$. oneidensis MR-1 was used to produce FeS-NPs after reacting with biogenic $\mathrm{S}^{2-}$, suggesting an environmental-friendly way for effectively coupling pollutant degradation and nanomaterial biosynthesis [149].

The biogenic $\mathrm{S}^{2-}$ produced by $S$. oneidensis MR-1 has also been applied to synthesize $\mathrm{Ag}_{2} \mathrm{~S}$ nanospheres with a mean diameter of $9 \pm 3.5 \mathrm{~nm}$ [150]. The produced biogenic $\mathrm{Ag}_{2} \mathrm{~S}$-NPs showed high biocompatibility without inhibition and cytotoxicity to both prokaryotic bacteria and eukaryotic cell lines, which was primarily attributed to the formed protein/peptide coating on the surfaces of biogenic nanoparticles during the biotransformation process [150, 151]. Small-sized and homogenous-shaped $\mathrm{CuS}-\mathrm{NPs}$ produced by $\mathrm{S}$. oneidensis MR-1 were reported as a candidate for photothermal therapy, which displayed a high photothermal conversion efficiency of $27.2 \%$ because of their strong absorption under infrared light [152]. Xiao et al. discovered a complex hollow $\mathrm{CuS}$ nano/ micro shells self-assembled on the $S$. oneidensis MR-1 cell surface, which possessed a hierarchical structure leading to a significant enhancement of $\mathrm{Cr}^{6+}$ removal capacity [153]. Spherical $\mathrm{ZnS}$ nanocrystals with an average diameter of $5 \mathrm{~nm}$ were bio-fabricated through utilizing biogenic $\mathrm{S}^{2-}$ produced by $S$. oneidensis MR-1 to precipitate $\mathrm{Zn}^{2+}$, and the product showed a high level of photodegradation efficiency of rhodamine B [154]. Recently, Chellamuthu et al. developed a genetic-control strategy to biosynthesize manganese-doped $\mathrm{ZnS}(\mathrm{Mn}: \mathrm{ZnS})$ nanoparticles with different doping levels (Fig. 5) [155]. The authors found that the Mn doping level changed as a function of added inducer when the engineered strain of S. oneidensis with inducible expression of MtrCAB complex was used to control the reduction of $\mathrm{Mn}^{4+}$ oxide. Impressively, these biogenically produced Mn:ZnS-NPs showed comparable physical and optoelectronic properties to chemically synthesized quantum dots. This work illustrates the promise of implementing synthetic gene circuits to controllable tune biogenic nanoparticles.
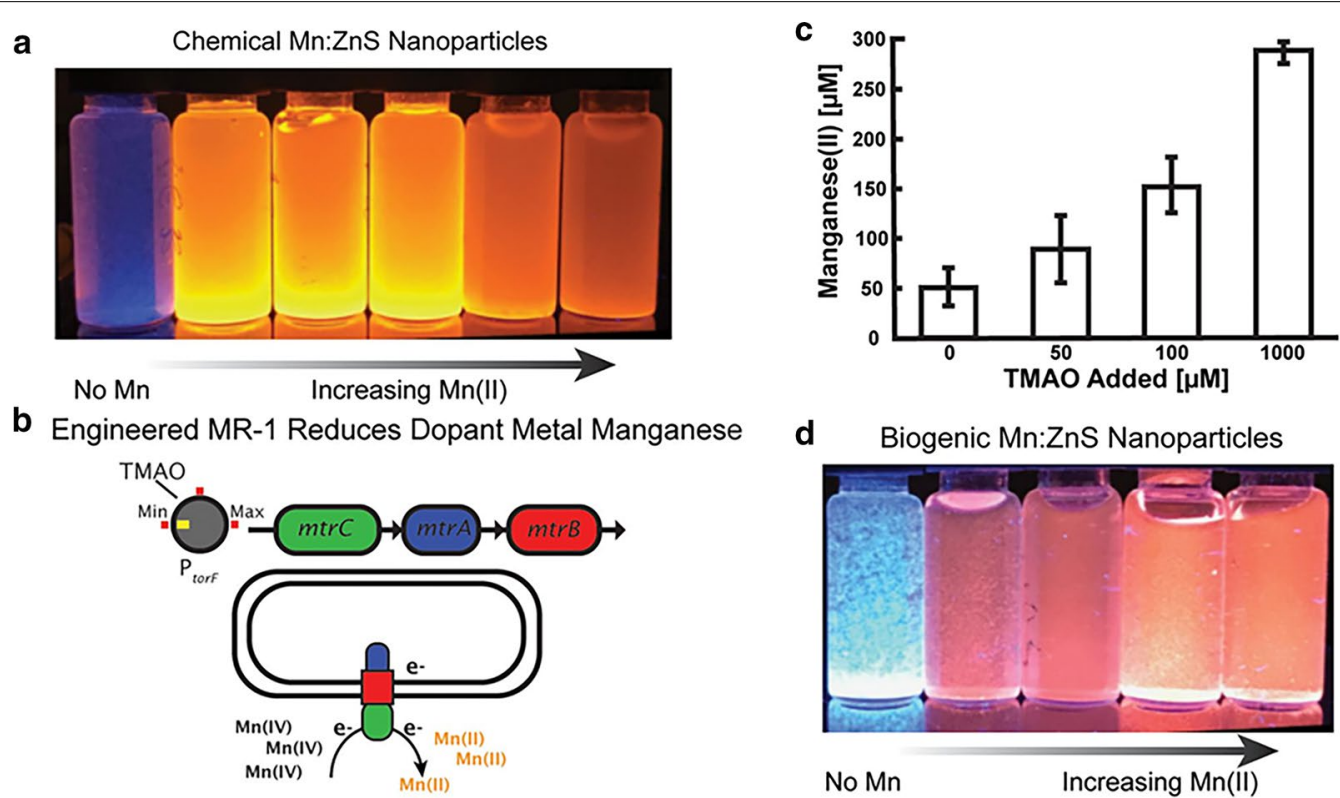

Fig. 5 Controlling manganese doping of ZnS quantum dots by engineered S. oneidensis JG3631 with the inducible expression of MtrCAB complex. $\mathbf{a}$ Chemically synthesized Mn doped ZnS NPs with varying optical properties, $\mathbf{b}$ the amount of the inducer (TMAO) regulating expression of MtrCAB complex that performs extracellular reduction, $\mathbf{c}$ relationship between $\mathrm{Mn}^{2+}$ concentration and the addition of TMAO, $\mathbf{d}$ biogenic Mn doped ZnS quantum dots with varying optical properties as a function of $\mathrm{Mn}^{2+}$ concentration [155]. 
Cadmium chalcogenides, especially $\mathrm{CdS}, \mathrm{CdSe}$ and $\mathrm{CdTe}$, are considered as quantum dots when their physical size is lower than the exciton Bohr radii, and their unique size-dependent characteristics including broad UV excitation, narrow emission, bright photoluminescence and high photostability, endowing them cuttingedge applications in bioimaging, optical devices like light-emitting diodes, solar energy conversion and sensors [156, 157]. The biosynthesis of Cd-based quantum dots is flourishing due to its prominent economic and environmental benefits [157]. Both S. oneidensis MR-1[158, 159] and G. sulfurreducens PCA[30] have been adopted to bio-fabricate CdS-NPs under anaerobic conditions. To avoid the particle agglomeration, ionic liquids were introduced as soft templates to control crystal growth and assist assembly of biogenic CdS [158]. Notably, the in-situ synthesis of CdS quantum dots on bacterial cell surfaces can construct a biotic-abiotic hybrid system for efficient bio-photoelectric reductive degradation of some organic pollutants such as trypan blue and methyl orange [30,159].

There is no doubt that how to realize high productivity and precisely control crystalline composition and structure always is a subject worth probing into. Tian et al. achieved the controllable production of Se-NPs and CdSe-NPs in S. oneidensis MR-1 cells, with fine-tuned composition and subcellular location, by genetically manipulating the EET chain (Fig. 6) [160]. The authors found that CdSe-NPs were mainly formed in the cytoplasm of the wild-type cells with $\mathrm{Se}^{0}$ nanoparticles in their periplasm. However, ultrafine, uniform-sized and fluorescence-characterized CdSe nanoparticles with an average diameter of $3.3 \pm 0.6 \mathrm{~nm}$ were produced after the CymA-encoding gene was deleted, but much larger aggregates consisting of Se-NPs were abundantly generated when the CymA expression level increased [160]. It is quite clear that these findings fundamentally reconfirm the feasibility of EET regulation strategies for developing fine-controllable nanoparticles biosynthesis technologies [81].

For comparison, a series of MNPs biosynthesized by taking advantage of vigorous EET features of Shewanella and Geobacter species are listed in Table 1, along with their properties and particular applications.

\section{Extraction and purification of biogenic metal nanoparticles} The extraction, concentration and purification of the biologically produced MNPs directly determine their practical applications and commercial competitiveness. Centrifugation is undoubtedly one of the most effective strategies to separate and concentrate MNPs due to its simplicity, low cost and easy scalability. Apparently, the biosynthetic route based on bacterial EET ability provides a distinct advantage for centrifugal separation and
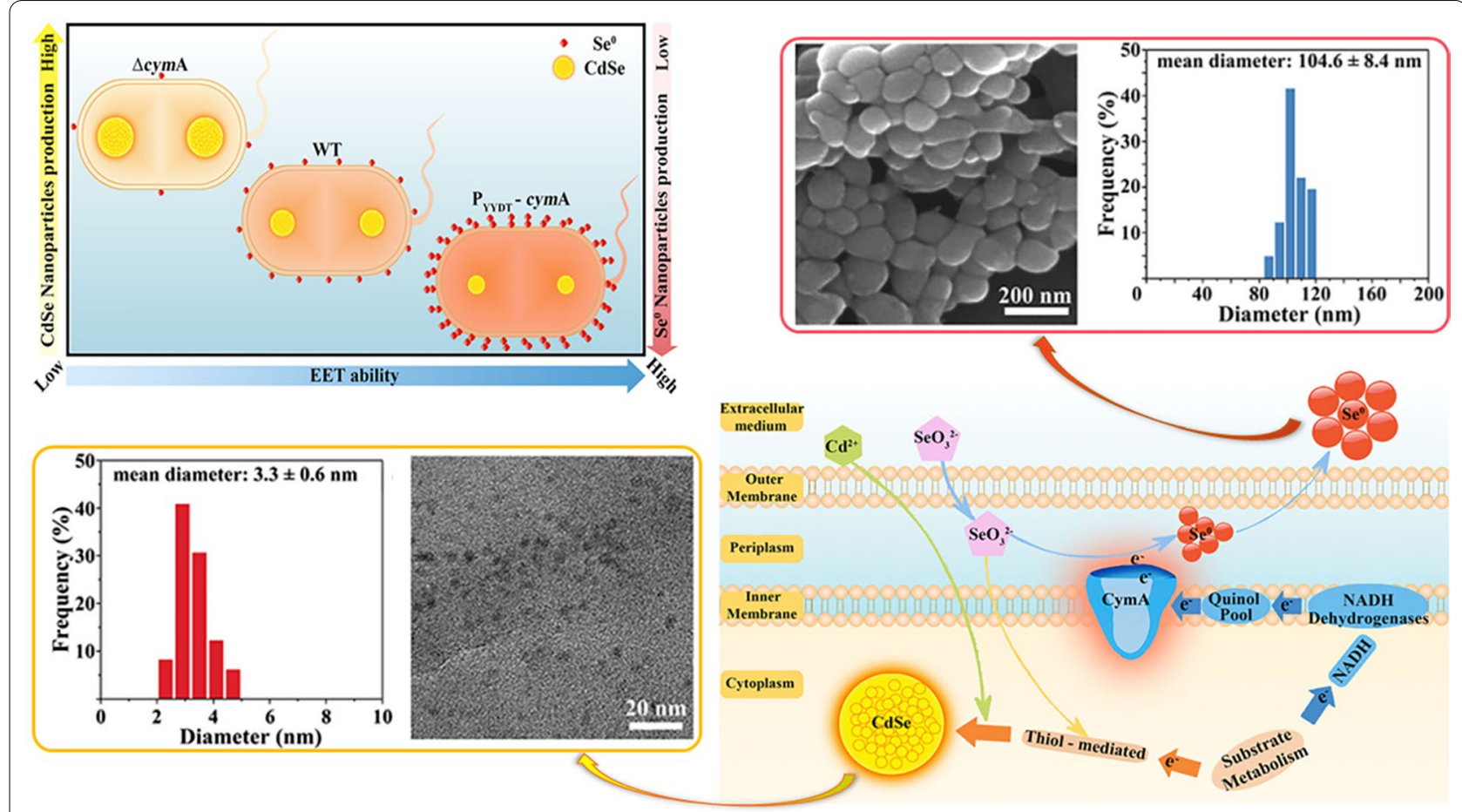

Fig. 6 Schematic diagram for the EET-dependent synthesis of Se-containing nanoparticles by S. oneidensis MR-1 [160] 


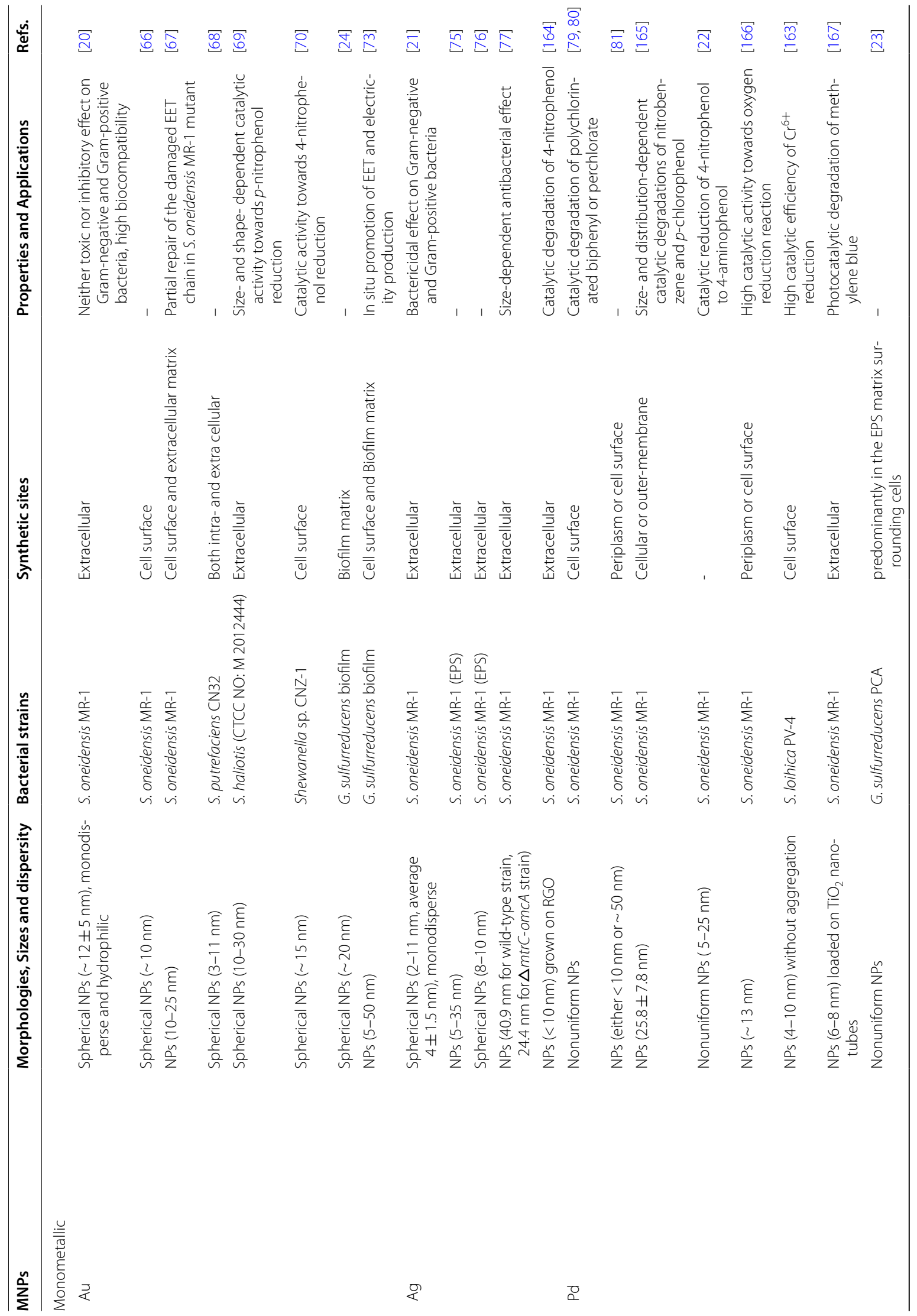




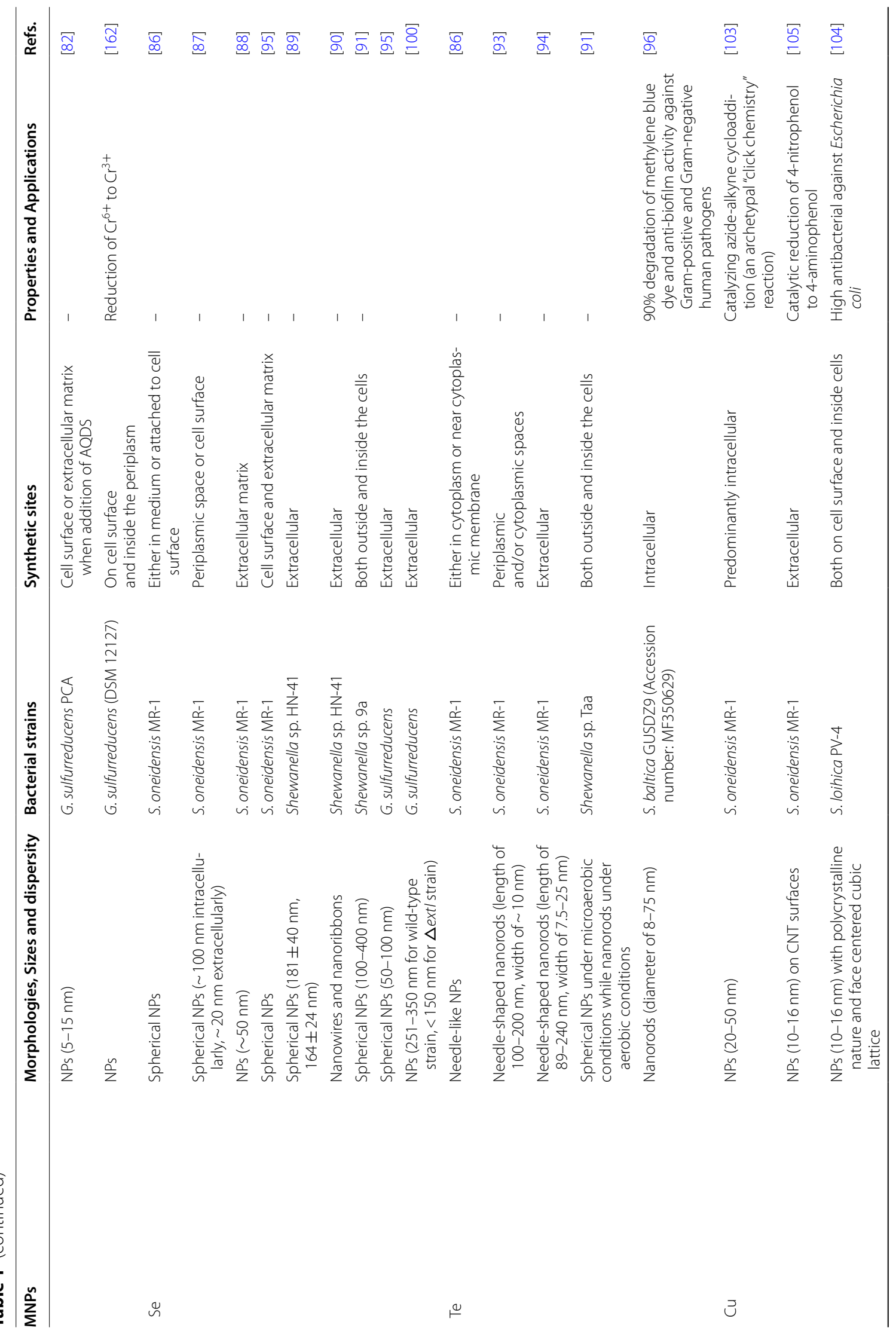




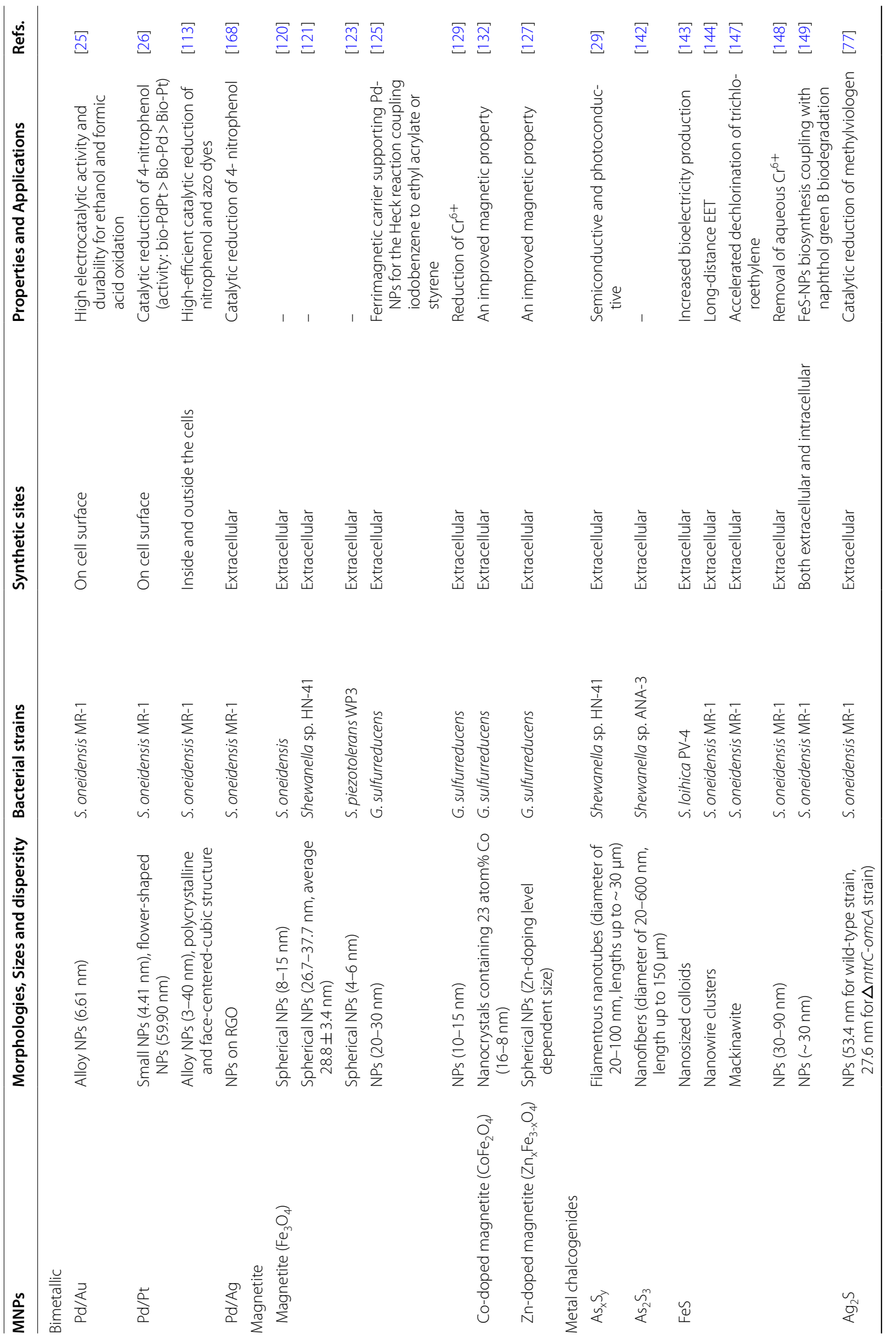




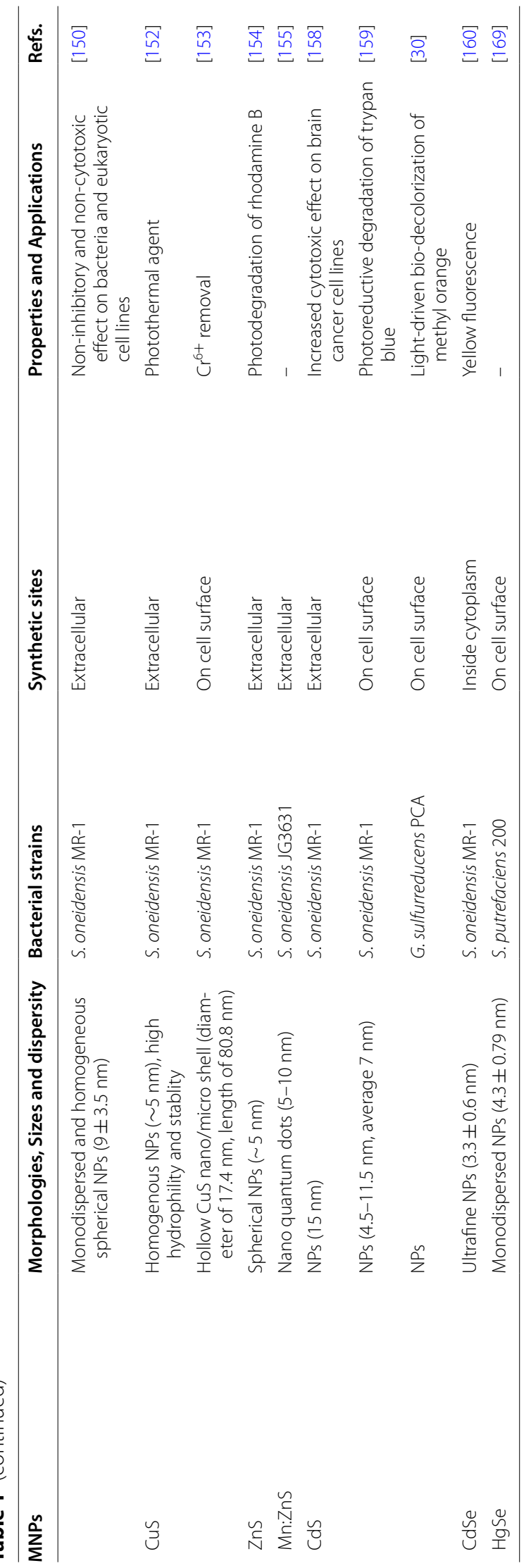


purification because many metal ions could be reduced directly to from corresponding MNPs outside the cells by taking advantage of the electrons that are transported out of the cells. In this case, the generated MNPs could be collected directly by simple centrifugation process. Generally, a two-step centrifugation strategy with different centrifugal forces was adopted: the low one ( $5000 \mathrm{~g})$ for firstly removing bacterial cells and the high one (up to $100,000 \mathrm{~g}$ ) for collecting MNPs subsequently [20, 21]. Besides, filter units were also applied to effectively concentrate MNPs from a large-volume reaction solution [161]. For extraction and purification of those MNPs either inside the cells or attached on cell surfaces, the release of them from bacterial cells through physical or biological disruption of cells (e.g. ultrasonic collapsing, autoclaving and lysozyme lysis) is unavoidable before centrifugal collection $[90,148]$. Remarkably, given the inherent and interesting features of Shewanella and Geobacter species themselves, a lot of studies have attempted to directly use the MNPs-hybridized cells without additional extraction and purification of MNPs for both bioelectricity production and pollutant removal with satisfactory performance, which not only simplifies the production process but also effectively integrates the merits of inorganic nanoparticles and bacterial cells $[24,34,69$, $73,146,162,163]$.

\section{Graphene oxide bioreduction}

Graphene has been becoming a celebrity in material science since its revolutionary discovery by Novoselov and co-workers [170]. Graphene possesses ultrahigh specific surface area and many appealing mechanical, electrical, optical and thermal properties [171]. Chemical oxidation of graphite to graphene oxide (GO) followed by the reduction treatment is a commonly used method for producing graphene [172]. Properties of the reduced graphene oxide (RGO) are dependent to a large extent on reductants and reduction conditions. Using chemical reductants such as hydrazine is an efficient approach with respect to large-scale production at a low cost, but many of them are potentially toxic to living organisms. In addition to use green reducing agents such as ascorbic acid [173], microbial reduction is an alternative strategy.

Five strains of Shewanella species were investigated by Salas et al. on the biological reduction activities towards the production of GO under anaerobic conditions, where the reduction was evident at $24 \mathrm{~h}$ for all of the bacteria although in varying degrees [31]. Impressively, physical characteristics such as conductivity of bacterially reduced GO were comparable to the chemically reduced counterpart, and the EET pathway of S. oneidensis MR-1 was demonstrated to play a significant role in the GO reduction because of an apparently impaired reduction ability with those strains deficient in each of outer membrane $c$-Cyts, but there is a puzzling finding in their work that the $\triangle c y m A$ mutant retained an almost unscathed ability in the GO reduction [31]. Soon after, Jiao et al. reported a quite contrary experimental phenomenon that the mutated S. oneidensis MR-1 lack of cymA gene was incapable of reducing GO [174]. Moreover, Yu and co-workers found that the kinetics of electron transfer from the purified protein OmcA to GO was obeyed the Michaelis-Menten equation, indicating that the electron transfer process was assigned to an enzyme catalytic characteristic [175]. Their further study on structure of OmcA/GO complex suggested that the formation of a hydrogen bond between the $-\mathrm{NH}_{2}$ group of amino acid residues and the $-\mathrm{COOH} /-\mathrm{OH}$ group of $\mathrm{GO}$ could shorten the interfacial electron transfer distance so as to mitigate the energy barrier. This work gives substantial evidences at the molecular level about bacterial $c$-Cyts mediated GO reduction.

In addition, electron-shuttling compounds such as riboflavin and AQDS can increase the GO reduction rate by several times because of their high electron-carrying capacities [174, 176]. Notably, the microbial reduction of GO was also observed in spite of the presence of oxygen, which meant that the strict anaerobic environment is not essential although that oxygen molecules are more favorable electron acceptors than GO [177, 178]. The occurrence of GO reduction under aerobic conditions might be ascribed to either an oxygen-lacking microenvironment where the oxygen was non-accessible or/and exhausted [177], or the chemical reduction executed by some specific biomolecules [178].

Assembly of 2-D graphene sheets serving as building blocks into 3-D architectures is extremely attractive because of their unique structure features with broad application range [179]. During the microbial reduction process, biogenic RGO can self-aggregate into 3-D conductive hydrogel complex together with bacterial cells, and the produced complex is usually referred to as hybridized biofilms [32, 180, 181]. Compared to those chemically assembled 3-D graphene architectures, the biological counterparts provide an elastic platform to integrate conductive graphene with luxuriant biological functions of bacteria.

It is noteworthy that the 2-D sheet structure is a promising host for the deposition of diverse nanoparticles. On account of the confirmed ability of DMRB to reduce both metal ions and GO, green and facile one-pot synthesis of functional hybrid nanomaterials consisting of MNPs and RGO can come true under an ambient condition. Dong et al. developed an Au-NPs/RGO nanohybrid synthesized by using $S$. oneidensis MR-1 without the addition of any toxic agents, which showed comparable structural 
features and a better catalytic activity towards the reductive removal of nitroaromatics [182]. The similar approaches have also been adopted to biosynthesize AgNPs/RGO [164], Pd-NPs/RGO [183], Pd-Au/RGO[25] and $\mathrm{Pd}-\mathrm{Ag} / \mathrm{rGO}[168]$ nanocomposites.

All of above studies demonstrate a simple, eco-friendly and cost-effective methodology for the fabrication of graphene-based nanocomposites with particular functionalities and application potentials.

\section{Applications}

\section{In-situ assembly of bioelectrodes}

A bioelectrode wiring electroactive bacterial cells to conductive solid interface is the core footstone to develop diverse microbial electrochemical systems [184, 185]. Notably, how to strengthen the bio-abiotic interfacial electron transport has always been a critical challenge, because the low efficiency of the process severely impedes the practical applications of microbial electrochemical devices [13]. Assembly of such a bioelectrode enveloped with hybridized biofilms in which functional nanomaterials are biosynthesized in-situ by bacterial cells and thereby form a cooperative alliance together with the cells is a productive route to remarkably enhance interfacial electron transfer. Yong et al. reported a pioneering work on the self-assembly of GO and S. oneidensis MR-1 to form the 3-D electroactive RGO-hybridized biofilm where the GO nanosheets acted as fishing nets to catch bacteria cells and was reduced in turn by the captured cells [32]. Inspiringly, the developed electroactive biofilm delivered a 25 -fold increase in the outward current (electron flux from bacterial cells to electrode) and 74-fold increase in the inward current (reversed electron flux) over that of the naturally occurring biofilm. The high incorporation of bacterial cells into the electrode and the enhanced direct EET pathway bridged by biogenic RGO were suggested to be responsible for the dramatical improvements. Afterwards the tactics of in-situ assembly of graphene/electroactive bacteria hybrid biofilms has been widely adopted to boost interfacial EET, leading to greatly improved performances of microbial electrochemical systems for bioelectricity production, carbon dioxide reduction and $\mathrm{Cr}^{6+}$ removal [186-188].

The in-situ incorporation of MNPs with fine conductivity and catalytic activity into electroactive biofilm is another emerging approach to aggrandize electrode performance, because the high-conductive nanoparticles attached on bacterial cells are expected to rescue the relatively poor conductivity of the cells. Inspired by this conception, Hou et al. constructed a 3-D conductive bio-network through in-situ synthesis of Pd-NPs by G. sulfurreducens PCA biofilm to improve the electron transfer, which achieved an over fivefold increase in both hydrogen evolution and the reductive degradation of nitro-, azo- and chloro-aromatics [189]. The incorporation of biogenic Au-NPs was also proved to greatly increase the conductivity of G. sulfurreducens PCA biofilm, leading to $40 \%$ increase in anodic current density [73]. To further break through the challenge of sluggish electron transfer between biosynthesized nanoparticles and an electrode, a ternary hybrid biofilm of Pd-NPs/ cells/RGO was developed recently through the simultaneous reduction of $\mathrm{Pd}^{2+}$ and $\mathrm{GO}$ using S. oneidensis MR-1 [190]. Compared to the binary control without RGO, electrochemical conductivity of the prepared PdNPs/cells/RGO hybrid biofilm increased from almost zero to $196 \mu \mathrm{S} \mathrm{cm}^{-1}$ because of the well-developed 3-D electron transfer network with the implantation of RGO. As a consequence, the ternary biofilm showed outstanding electrocatalytic activity in terms of 36.7- and 17.2-fold increase in steady state current density towards hydrogen evolution and nitrobenzene reduction, respectively.

Except for noble metal nanoparticles, nanosized FeS biosynthesized during the Shewanella biofilm maturation was demonstrated to significantly enhance bioelectricity production as well [143, 144], where the biogenic FeS-NPs were regarded as extracellular electron conduits wiring the electron-producing cells to the solid electrode. Very recently, $\mathrm{Yu}$ and co-workers proposed a new concept of a single cell electron collector, which was in-situ built with an interconnected intact conductive layer on and cross an individual cell membrane [34]. The single cell electron collector assembled with biogenic FeS-NPs was proved to achieve a record-high interfacial electron transfer efficiency and electricity production (Fig. 7). The improvement could be attributed to the fact that the FeSNPs wrapped around cell surface of S. oneidensis MR-1 wired the MtrC/OmcA-MtrB-MtrA transmembrane electron conduits to electrode, while others in the periplasm bridged the periplasm-terminated conduits such as polysulfide reductase PsrABC (a bio-complex responsible for FeS biosynthesis). This innovative work opens a new window for abiotic/biotic interface engineering to improve interfacial electron transfer efficiency from macro-population levels to single-cell levels.

\section{Nano-catalysts for energy conversion}

Nanostructured metal materials especially noble metals are the most commonly used catalysts for various energy conversion reactions because of their incomparable reactivities [191]. Not surprisingly, biogenic MNPs synthesized by DMRB have also cut a figure in this area.

As one case, nano-sized Pd particles produced by $S$. oneidensis MR-1 cells have been exploited as effective oxygen reduction catalysts for fuel cells and metal-air batteries [166]. After simple $\mathrm{KOH}$ activation at $420{ }^{\circ} \mathrm{C}, S$. 
a
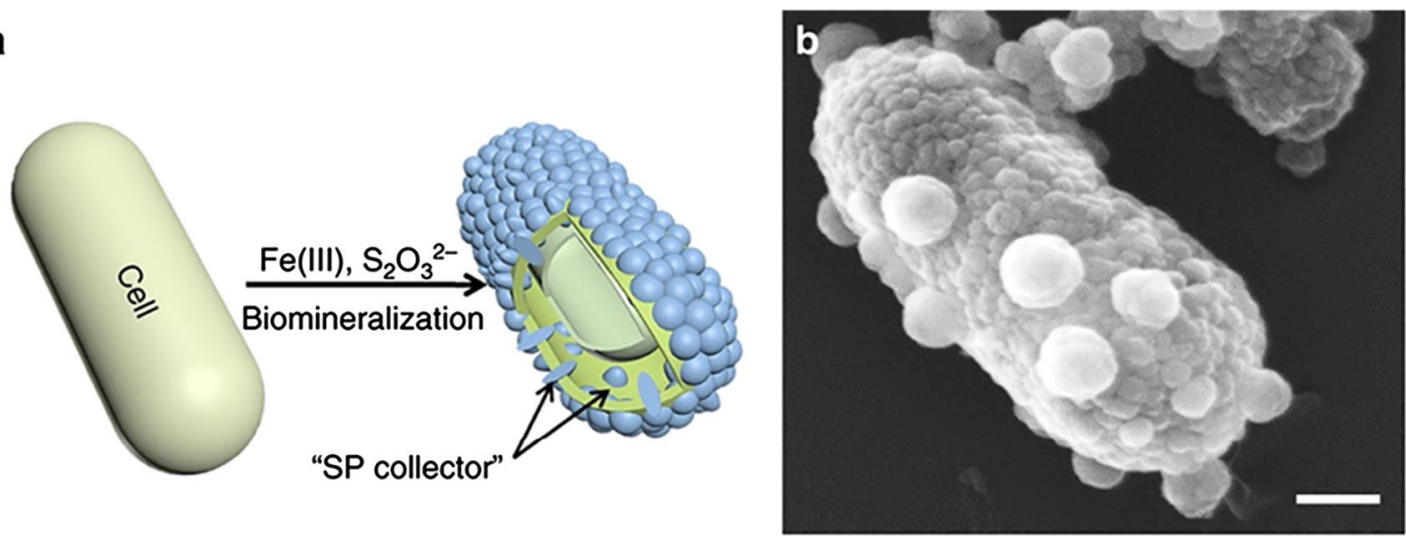

C

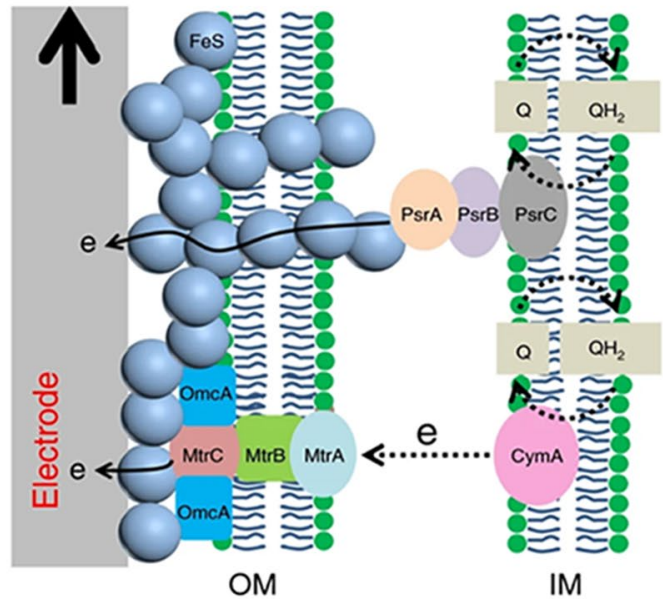

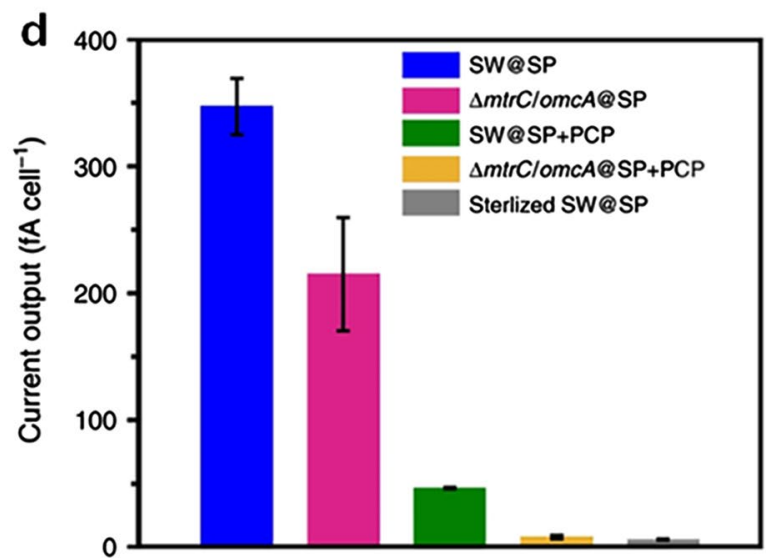

Fig. 7 A single cell electron collector in-situ assembled with biogenic FeS-NPs for significantly increasing interfacial electron transfer efficiency at the single-cell level and electricity production. a Schematic illustration of the FeS-NPs-based collector assembly, b SEM image of S. oneidensis MR-1 cell coated with FeS-NPs, c proposed electron transfer pathway from the cell as the electron collector to an electrode, $\mathbf{d}$ current output of the cell under different conditions [34]

oneidensis MR-1 cells were converted into highly porous heteroatom-doped carbon supporting uniform Pd-NPs, and consequently, the as-prepared hybrid nanomaterials showed 2.2-fold higher specific mass catalytic activity, better durability and methanol tolerance compared to the commercial Pt/C catalyst. Recently, Wang et al. synthesized a Pd/RGO hybrid catalyst through using S. oneidensis MR-1 as the biological reducing agent, which showed promising electrocatalytic activity towards oxygen reduction reaction in alkaline electrolyte [183]. Jiang and coworkers fabricated another efficient oxygen reduction catalyst of $\mathrm{Mn}_{2} \mathrm{O}_{3}$ micro-/nanocubes through calcination of biogenic $\mathrm{MnCO}_{3}$ precursors that were produced by $S$. loihica PV-4 in the presence of $\mathrm{MnO}_{4}{ }^{-}$as the sole acceptor [192].

The bacteria-derived MNPs have also been tried as Liion storage materials. For instance, S. oneidensis MR-1 was reported to synthesize Te nanorods made up of helically-twisted atomic-wire bundle structure, which gave an unique Li-ion uptake characteristic [98]. The thermal carbonization of these biogenic Te nanorods together with bacterial cells provided a well-defined encapsulation of Te nanorods into carbon matrix, leading to an increased electrical conductivity and enhanced battery performance. More notably, these biogenic Te nanorods behaved the reversible Li-ion uptake without structural deterioration owing to their unusual anionic redox chemistry and structural flexibility. For another example, $\mathrm{As}_{4} \mathrm{~S}_{4}$ clusters with unique molecular-cage-like structure produced by Shewanella sp. HN-41 were adopted as highperformance Li-ion active storage materials [141].

In general, the biogenic MNPs cannot be used directly as electrocatalysts because of the coexistence of poorconductive cell substrates. Therefore, a high-temperature carbonization approach mentioned above are usually involved in the preparation process $[98,166]$. As an alternative, a simple hydrothermal reaction has been also proposed to convert non-conducting cell biomass into 
heteroatom doped carbon matrix with porous structure and high conductivity. For instance, a 3D porous bio-PdAu/RGO catalyst was harvested through a facile hydrothermal treatment of bacteria/PdAu/GO hybrid biofilm, which exhibited a better electrocatalytic activity and durability towards oxidation of both ethanol (alkaline condition) and formate (acidic condition) compared to a commercial Pd/C [25].

Noteworthily, the bacterial biomass is a kind of versatile precursors with a distinguishing feature of in-situ heteroatom doping, which is expected to open up a horizon into elastically tailoring the characteristics of biogenic catalysts.

\section{Organic pollutant degradation}

As showed in Table 1, numerous biogenic MNPs and their derivatives have been used widely as nanocatalysts for degradation of various organic pollutants, especially 4-chlorophenol and azo dyes. For instance, Au-NPs biosynthesized by $S$. haliotis were found to behaved size- and shape-dependent catalytic activity towards 4-nitrophenol reduction using sodium borohydride $\left(\mathrm{NaBH}_{4}\right)$ as chemical reductants, of which the spherical and small particles gained the highest activity with a rate constant of $0.665 \mathrm{~min}^{-1}$ [69]. Another, the bio-Pd/Pt alloy nanoparticles produced by $S$. oneidensis MR-1 also showed high activity to 4-nitrophenol reduction, while there was a gradual downturn of catalytic activity [26].

Controlling the particle size distribution and preventing the unfavorable aggregation of nanoparticles in the process are of importance for their activities and durabilities in practical applications. Carbon nanomaterials having high surface area, conductivity and stability are very promising to address this concern. Various biogenic MNPs including Ag-NPs [193], Cu-NPs[105] and Pd/ Ag alloys[168] have been integrated into either carbon nanotubes or graphene as efficient catalysts for organic contaminant removal. Additionally, the conversion of bacterial cell biomass to porous carbon matrix through $\mathrm{KOH}$ activation at a high temperature was also developed to improve the catalytic activity of biogenic Pd-NPs [22]. The as-activated catalysts delivered a high-performance catalytic reduction of 4-nitrophenol to 4-aminophenol with an outstanding apparent kinetic constant of $5.0 \times 10^{-3} \mathrm{~s}^{-1}$, comparable to the commercial $\mathrm{Pd} / \mathrm{C}(5.0$ wt\%). Biogenic FeS-NPs synthesized by Shewanella spp. have been reported to dramatically accelerate dechlorination of both carbon tereachloride and trichloroethylene by a factor of over five compared to the abiotic FeS [147].

The application of biogenic MNP-based catalysts has indeed made great progress in assisting the chemical degradation of organic pollutants, while such methodology usually needs to use toxic chemicals as reductants.
Both photo-catalytic and bio-catalytic degradation without the use of harmful reagents are much more favorable. Impressively, the in-situ formation of biogenic CdS quantum dots on the cell surface of G. sulfurreducens PCA and S. oneidensis MR-1 provided an opportunity to develop an attractive hybrid pattern that integrated biological degradation with ligh-excited photoelectrons (Fig. 8) [30, 159]. Such a bio-photo-catalytic system opened a new high-powered strategy for pollutant degradation through interactions among light energy, electrochemical reactions and microorganisms. Besides, biosynthesized PdNPs and RGO were incorporated into S. oneidensis MR-1 biofilm for significantly improving bioelectrochemical removal of nitrobenzene, because these biogenic nanomaterials constructed a fast electron transfer network in electrode biofilms [190]. Observably, the development of biohybrid systems together with biogenic nanomaterials holds great competitiveness in pollutant degradation.

\section{Heavy metal removal and recycling}

Heavy metal pollution poses serious threat to both human health and environmental safety. In contrast to organic pollutants that can be effectively degraded, heavy metals can only be treated by adsorption separation or/ and (bio-)chemical transformation that produce insoluble precipitates with less toxicity. Not only can microorganisms serve as bio-adsorbents for heavy metals, but also drive their bio-transformation for detoxication [157]. It is well known that DMRB can efficiently reduce various metal ions with relatively high redox potentials under anaerobic conditions, and consequently transform toxic heavy metal ions into functional nanomaterials.

As an important complement to microbial recycling, the application of biogenic nanomaterials especially MNPs for the detoxification of heavy metal pollution is also illuminated recently. Hexavalent chromium $\left(\mathrm{Cr}^{6+}\right)$, one of the most prevalent heavy metal contaminants, is approximately 100 folds more toxic and 1000 folds more mutagenic than its reduced form of $\mathrm{Cr}^{3+}$ with much less solubility and mobility in aqueous environment [194], and thus the reductive transformation of $\mathrm{Cr}^{6+}$ to $\mathrm{Cr}^{3+}$ is a generally approving way to remediate $\mathrm{Cr}^{6+}$ pollution. Biogenic Pd-NPS produced by both Shewanella[163] and Geobacter species[162] exhibited high removal capacities for $\mathrm{Cr}^{6+}$. The nanostructured $\mathrm{FeS}$ is another attractive candidate for $\mathrm{Cr}^{6+}$ reduction since both $\mathrm{Fe}^{2+}$ and $\mathrm{S}^{2-}$ are excellent reductants. The feasible removal of aqueous $\mathrm{Cr}^{6+}$ pollution by biogenic FeS-NPs was reported by $\mathrm{Yu}$ et al. and the removal efficiency was dependent on the particle size [148]. Taking into consideration of their inherent abilities to biological reduce metal ions, the DMRB cells hybridized with biogenic MNP are very 
a

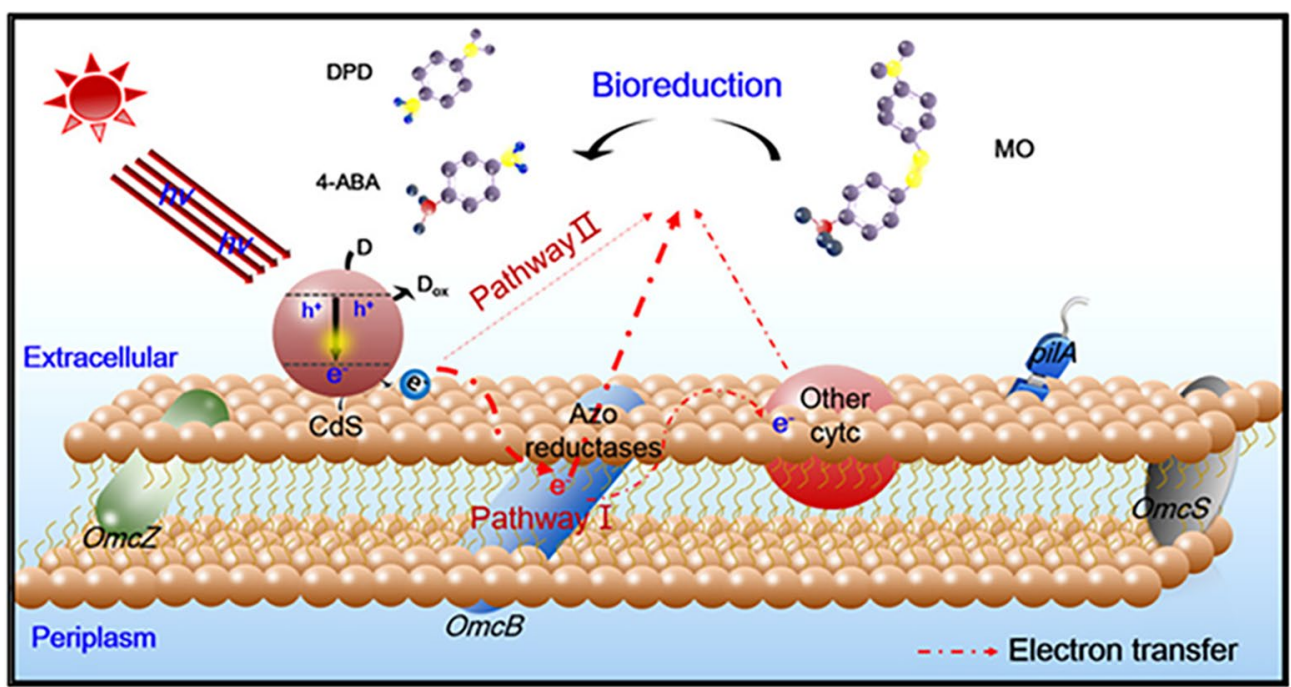

b

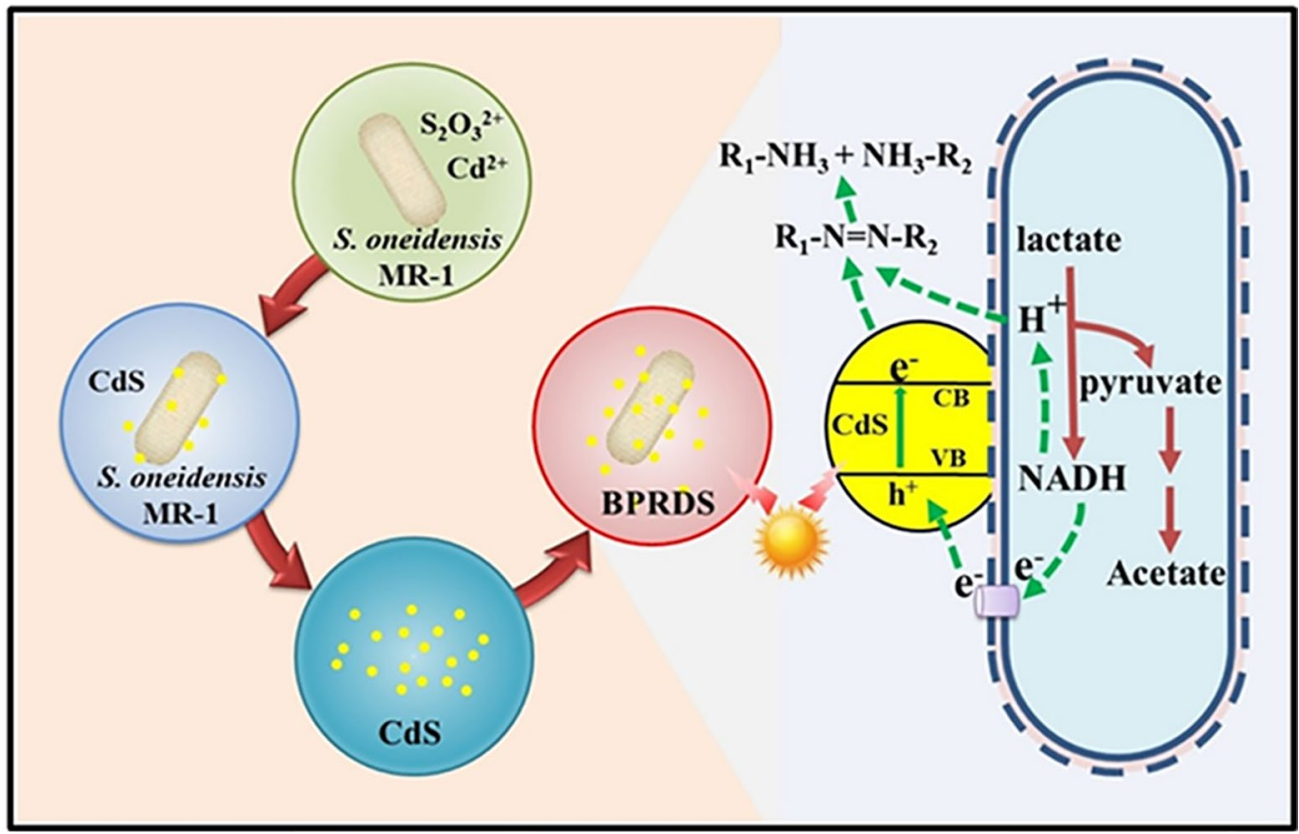

Fig. 8 Bio-photo-catalytic systems produced through in-situ assembling biogenic CdS quantum dots into cells. a CdS-hybridized G. sulfurreducens PCA for bio-photo-catalytic degradation of methyl orange (MO).[30] b CdS-hybridized S. oneidensis MR-1 for bio-photo-catalytic degradation of trypan blue [159]

expected to remove toxic metal pollution due to the potential merit of bio-abiotic interactions [162].

Nanoscale magnetite is also an attractive material for removing toxic heavy metals due to its especial magnetic recoverability [131]. Impressively, the biogenic magnetite nanoparticles achieved a higher $\mathrm{Cr}^{6+}$ removal efficiency (almost 100\%) than the chemically synthesized counterpart (82\%), because the negative-charged organic coating could effectively enhance electrostatic adsorption of positive-charged chromium ions for the former [195].

\section{Antimicrobial activity and therapy}

Ag-NPs are considered promising for combating bacteria due to their low cytotoxicity and remarkable antimicrobial activity against both Gram-positive and Gram-negative bacteria [196]. Much effort has been devoted to chemically synthesize shape-controllable Ag-NPs for pharmaceutical applications. Nevertheless, biogenic AgNPs synthesized by $S$. oneidensis MR-1 were found to present stronger toxicity for all targeted bacterial strains including E. coli, S. oneidensis and B. subtilis compared 
to chemically synthesized ones such as colloidal-Ag and oleate capped Ag-NPs [21]. The nanoparticle surface coatings appear to play a critical role in the antimicrobial activity of biogenic Ag-NPs, while further investigations are needed to explore underlying mechanism. The antibacterial activity of Ag-NPs seemed size-dependent, and increased with a decrease in the particle diameter [77]. A biogenic Ag/RGO hybrid, the Shewanella-synthesizing Ag-NPs with a diameter $<10 \mathrm{~nm}$ growing on RGO without aggregation, showed an excellent sterilization capacity up to $99.9 \%$ against $E$. coli when used at a dosage of $2 \mathrm{mg} / \mathrm{L}$ for $15 \mathrm{~min}$, and the rapid release of $\mathrm{Ag}^{+}$ to enhance the bacteria-bactericide interaction and the strong convolution of bacterial cells by RGO were considered to make contributions to the high antibacterial activity [164]. Biogenic Cu-NPs[104] and Te-NPs[96] also showed antibacterial activity against several pathogenic bacteria.

Biogenic MNPs are also attracting widespread interest in their applications in other biomedical fields. Nanostructured $\mathrm{CuS}$, one kind of cheap semiconductors with strong and stable absorption in near infrared region, is a promosing candidate for photothermal therapy. Zhou et al. fabricated homogenous CuS-NPs with small size $(\sim 5 \mathrm{~nm})$ by S. oneidensis MR-1 and evaluated their performance in photothermal therapy for the first time [152]. The biogenic CuS-NPs showed a high photothermal conversion efficiency of $27.2 \%$ due to their strong absorption of the infrared irradiation, indicating their potentials as a photothermal therapy agent. As another example, CdS-NPs produced by S. oneidensis MR-1 with ionic liquid as soft template exhibited excellent cytotoxicity against brain cancer cell lines using rat glioma cell lines [158].

\section{Conclusions and perspectives}

The potential use of nanosized materials in various areas triggers the increasing need to produce them in stable and tailorable formulations with environmentalfriendly processes. There is therefore ongoing research for implementing biotechnological and green synthesis methodologies. Microorganisms, as powerful biological nanofactories, have proven themselves capable of rapidly synthesizing various nano-scale materials, especially MNPs.

Shewanella and Geobacter species with specific EET pathways are competitive over other microorganisms in controllable synthesis of MNPs with well-defined sizes and structures, since they can directly synthesize MNPs through extracellular reduction without a need for transporting metal ions into the cells. Furthermore, the extracellular dissimilatory reduction abilities of Shewanella and Geobacter species allow them to produce biological
RGO and hybrid materials together with various MNPs. Indeed, both direct EET via membrane-bound $c$-Cyts (Mtr proteins for Shewanella and Omc proteins for Geobacter) and indirect EET mediated by self-secreted electron shuttles like flavins have been evidenced to transport intracellular electrons (reducing equivalents) across the cell membrane barriers for the reduction of metal ions ot/and GO outside the cells, thus resulting in the formation of inoganic nanomaterials. Apart from the well-controlled nanostructures and physicochemical properties, the bacterial EET-driven synthesis route has also been illustrated substantially to make nanoproducts more biocompatible than the chemically produced counterparts in general, because such biological methodology adpotes biological constituents (e.g. proteins and bio-active small molecules) instead of chemcial reagents (e.g. reducing, capping and stabilizing agents) that are usually required for the chemical synthesis. The biogenic nanomaterials with non- or low-cytotoxicity are of great promise in biomedical application. It is predictable that the biosynthestic route is competitive economically in view of the low-cost and renewbale bacterial cells acting as nanofabricating biofactories and the fast biosynthesis rate (the time required for biosynthesizing MNPs could be as low as several minutes). What's more, the biological synthesis gives a promise to self-assemble inorgnic/biotic hybrid systems through in-situ formation of inorgnic nanomaterials interfacing with bactterial cells, which not only provides a new platform to study the biotic/abiotic interfacial interaction but also broadens the application range from classical areas (e.g. antibacterial and inorganic catalysis) to some emerging interdisciplinary disciplines such as bioelectrocatalysis and biophotocatalysis.

Although achieving great advances in nanobiosynthesis using Shewanella and Geobacter species as cell factories, there is still much to do to accurately tune sizes, nanostructures and properties of the biogenic nanoproducts for designated applications. In-depth elucidation and control of the EET route is beyond all doubt the key to achieve this goal. Over the past decade, studies on mechanisms underlying the bacterial EET of Shewanella and Geobacter species have made substantial progress using solid electrodes electron acceptors, but an understanding regarding how the EET pathways take part in the formation of inorganic nanoparticles is still in its infancy. Clear bioformation on the EET pathways is the foundation of controlling the sizes, shapes, locations and dispersities of nanoproducts, and advanced omics technologies such as differential proteomics combined with genomics will be helpful in identifying the key proteins or/and electron transport routes involved in the nanoparticle biosynthesis for the design and construction of new biological entities under the guidance of synthetic biology strategy to 
produce custom-tailored nanomaterials. Noteworthily, the artificial construction of biological/inorganic hybrids that tactfully combine functional inorganic nanomaterials with bacterial vitalities are gaining great popularity.

Nanobiotechnology is highly interdisciplinary, which requires collaboration between different sciences including biology, nanoscience, materials science, chemistry, etc. We envision that with continuous progresses in the biosynthesis mechanisms and biotic/abiotic techniques, the versatile EET feature of microorganisms will unfold greater success in the biosynthesis of inorganic nanomaterials and their applications. The feasibility for the biological production of MNPs on industrial scales is also a crucial point to be considered, in particular their extracellular production, which is of great significance for product recovery. So far, only a few studies have reported the scale-up production of biogenic MNPs. As a result, how to increase the productivity of extracellular MNPs needs more attention in the future.

\section{Acknowledgements}

The authors acknowledge the Nanchang Key Laboratory of Microbial Resources Exploitation \& Utilization from Poyang Lake Wetland, Nanchang, China.

\section{Authors' contributions}

LZ, FZ contributed in collecting literature and preparing the original manuscript. ZL edited and corrected the manuscript. YH conceived the idea and revised the manuscript. All authors read and approved the final manuscript.

\section{Funding}

This work was supported by the National Natural Science Foundation of China (No. 31900109 and 31960015), the Natural Science Foundation of Jiangxi Province (No. 20202ACB215001), the Natural Science Foundation of Shandong Province (No. ZR2020QC009), and the Project of Graduate Innovation Foundation from Education Department of Jiangxi Province (No. YC2020-S181), China.

\section{Availability of data and materials}

Without restrictions.

\section{Declarations}

Ethics approval and consent to participate

Not applicable.

\section{Consent for publication}

All authors gave their consent for publication.

\section{Competing interests}

The authors declare that they have no competing interests.

Received: 26 March 2021 Accepted: 20 April 2021

Published online: 27 April 2021

\section{References}

1. Pereira L, Mehboob F, Stams AJM, Mota MM, Rijnaarts HHM, Alves MM Metallic nanoparticles: microbial synthesis and unique properties for biotechnological applications, bioavailability and biotransformation. Crit Rev Biotechnol. 2015;35(1):114-28.

2. Singh P, Kim Y-J, Zhang D, Yang D-C. Biological synthesis of nanoparticles from plants and microorganisms. Trends Biotechnol. 2016;34(7):588-99.
3. Duan H, Wang D, Li Y. Green chemistry for nanoparticle synthesis. Chem Soc Rev. 2015;44(16):5778-92.

4. Chen Z, Liu C, Cao F, Ren J, Qu X. DNA metallization: principles, methods, structures, and applications. Chem Soc Rev. 2018;47(11):4017-72.

5. Biswas A, Bayer IS, Biris AS, Wang T, Dervishi E, Faupel F. Advances in top-down and bottom-up surface nanofabrication: techniques, applications \& future prospects. Adv Colloid Interface Sci. 2012;170(1-2):2-27.

6. Kratosova G, Holisova V, Konvickova Z, Ingle AP, Gaikwad S, Skrlova K, Prokop A, Rai M, Placha D. From biotechnology principles to functional and low-cost metallic bionanocatalysts. Biotechnol Adv. 2019;37(1):154-76.

7. Singh J, Dutta T, Kim K-H, Rawat M, Samddar P, Kumar P. "Green" synthesis of metals and their oxide nanoparticles: applications for environmental remediation. J Nanobiotechnol. 2018;16:84.

8. Zhu K, Ju Y, Xu J, Yang Z, Gao S, Hou Y. Magnetic nanomaterials: chemical design, synthesis, and potential applications. Accounts Chem Res. 2018;51(2):404-13.

9. LiY-F, Chen C. Fate and toxicity of metallic and metal-containing nanoparticles for biomedical applications. Small. 2011;7(21):2965-80.

10. Iravani S, Varma RS. Bacteria in heavy metal remediation and nanoparticle biosynthesis. ACS Sustain Chem Eng. 2020;8(14):5395-409.

11. Shi L, Dong H, Reguera G, Beyenal H, Lu A, Liu J, Yu H-Q, Fredrickson JK. Extracellular electron transfer mechanisms between microorganisms and minerals. Nat Rev Microbiol. 2016;14(10):651-62.

12. Logan BE, Rossi R, Ragab Aa, Saikaly PE. Electroactive microorganisms in bioelectrochemical systems. Nat Rev Microbiol. 2019;17(5):307-19.

13. Zou L, Qiao Y, Li CM. Boosting microbial electrocatalytic kinetics for high power density: insights into synthetic biology and advanced nanoscience. Electrochem Energy Rev. 2018;1 (4):567-98.

14. Kim T-Y, Kim MG, Lee J-H, Hur H-G. Biosynthesis of nanomaterials by Shewanella species for application in lithium ion batteries. Front Microbiol. 2018;9:2817.

15. Lovley DR, Stolz JF, Nord GL, Phillips EJP. Anaerobic production of magnetite by a dissimilatory iron-reducing microorganism. Nature. 1987:330(6145):252-4.

16. Lovley DR, Giovannoni SJ, White DC, Champine JE, Phillips EJ, Gorby YA, Goodwin S. Geobacter metallireducens gen. nov. sp. Nov., a microorganism capable of coupling the complete oxidation of organic compounds to the reduction of iron and other metals. Arch Microbiol. 1993;159(4):336-44.

17. Myers $\mathrm{CR}$, Nealson $\mathrm{KH}$. Bacterial manganese reduction and growth with manganese oxide as the sole electron acceptor. Science. 1988;240(4857):1319-21.

18. Caccavo F Jr, Lonergan DJ, Lovley DR, Davis M, Stolz JF, Mclnerney MJ. Geobacter sulfurreducens sp. Nov., a hydrogen- and acetate-oxidizing dissimilatory metal-reducing microorganism. Appl Environ Microbiol. 1994;60(10):3752-9.

19. Shi M, Jiang Y, Shi L. Electromicrobiology and biotechnological applications of the exoelectrogens Geobacter and Shewanella spp. Sci China Technol Sci. 2019;62(10):1670-8.

20. Suresh AK, Pelletier DA, Wang W, Broich ML, Moon J-W, Gu B, Allison DP, Joy DC, Phelps TJ, Doktycz MJ. Biofabrication of discrete spherical gold nanoparticles using the metal-reducing bacterium Shewanella oneidensis. Acta Biomater. 2011;7(5):2148-52.

21. Suresh AK, Pelletier DA, Wang W, Moon J-W, Gu B, Mortensen NP, Allison DP, Joy DC, Phelps TJ, Doktycz MJ. Silver nanocrystallites: biofabrication using Shewanella oneidensis, and an evaluation of their comparative toxicity on Gram-negative and Gram-positive bacteria. Environ Sci Technol. 2010;44(13):5210-5.

22. Xiong L, Zhang X, Huang Y-X, Liu W-J, Chen Y-L, Yu S-S, Hu X, Cheng L, Liu D-F, Yu H-Q. Biogenic synthesis of Pd-based nanoparticles with enhanced catalytic activity. ACS Appl Nano Mater. 2018;1 (4):1467-75.

23. Yates MD, Cusick RD, Logan BE. Extracellular palladium nanoparticle production using Geobacter sulfurreducens. ACS Sustain Chem Eng. 2013;1 (9):1165-71.

24. Tanzil AH, Sultana ST, Saunders SR, Dohnalkova AC, Shi L, Davenport $\mathrm{E}$, Phuc H, Beyenal H. Production of gold nanoparticles by electroderespiring Geobacter sulfurreducens biofilms. Enzyme Microb Technol. 2016;95:69-75. 
25. Liu J, Zheng Y, Hong Z, Cai K, Zhao F, Han H. Microbial synthesis of highly dispersed PdAu alloy for enhanced electrocatalysis. Sci Adv. 2016;2(9):e1600858.

26. Tuo Y, Liu G, Dong B, Yu H, Zhou J, Wang J, Jin R. Microbial synthesis of bimetallic PdPt nanoparticles for catalytic reduction of 4-nitrophenol. Environ Sci Pollut Res. 2017;24(6):5249-58.

27. Jiang S, Kim M-G, Kim IY, Hwang S-J, Hur H-G. Biological synthesis of free-standing uniformed goethite nanowires by Shewanella sp HN-41. J Mater Chem A. 2013:1(5):1646-50.

28. Wright MH, Farooqui SM, White AR, Greene AC. Production of manganese oxide nanoparticles by Shewanella species. Appl Environ Microbiol. 2016;82(17):5402-9.

29. Lee J-H, Kim M-G, Yoo B, Myung NV, Maeng J, Lee T, Dohnalkova AC, Fredrickson JK, Sadowsky MJ, Hur H-G. Biogenic formation of photoactive arsenic-sulfide nanotubes by Shewanella sp strain HN-41. Proc Natl Acad Sci USA. 2007;104(51):20410-5.

30. Huang S, Tang J, Liu X, Dong G, Zhou S. Fast light-driven biodecolorization by a Geobacter sulfurreducens-CdS biohybrid. ACS Sustain Chem Eng. 2019;7(18):15427-33.

31. Salas EC, Sun Z, Luttge A, Tour JM. Reduction of graphene oxide via bacterial respiration. ACS Nano. 2010;4(8):4852-6.

32. Yong $Y-C, Y u$ Y-Y, Zhang $X$, Song $H$. Highly active bidirectional electron transfer by a self-assembled electroactive reduced-graphene-oxidehybridized biofilm. Angew Chem Int Edit. 2014;53(17):4480-3.

33. Wu X, Zhao F, Rahunen N, Varcoe JR, Avignone-Rossa C, Thumser AE, Slade RCT. A role for microbial palladium nanoparticles in extracellular electron transfer. Angew Chem Int Edit. 2011;50(2):427-30.

34. Yu Y-Y, Wang Y-Z, Fang Z, Shi Y-T, Cheng Q-W, Chen Y-X, Shi W, Yong Y-C. Single cell electron collectors for highly efficient wiring-up electronic abiotic/biotic interfaces. Nat Commun. 2020;11(1):4087.

35. Potter M. Electrical effects accompanying the decomposition of organic compounds. Proc Roy Soc B Biol Sci. 1911;84:260-76.

36. Kumar A, Hsu LH-H, Kavanagh P, Barriere F, Lens PNL, Lapinsonniere L, Lienhard JH, Schroeder U, Jiang X, Leech D. The ins and outs of microorganism-electrode electron transfer reactions. Nat Rev Chem. 2017;1(3):0024.

37. Marritt SJ, Lowe TG, Bye J, McMillan DGG, Shi L, Fredrickson J, Zachara J, Richardson DJ, Cheesman MR, Jeuken LJC, Butt JN. A functional description of CymA, an electron-transfer hub supporting anaerobic respiratory flexibility in Shewanella. Biochem J. 2012;444:465-74.

38. Leys D, Meyer TE, Tsapin AS, Nealson KH, Cusanovich MA, Van Beeumen JJ. Crystal structures at atomic resolution reveal the novel concept of "electron-harvesting" as a role for the small tetraheme cytochrome $c$. J Biol Chem. 2002;277(38):35703-11.

39. Schuetz B, Schicklberger M, Kuermann J, Spormann AM, Gescher J. Periplasmic electron transfer via the c-type cytochromes MtrA and FccA of Shewanella oneidensis MR-1. Appl Environ Microbiol. 2009;75(24):7789-96.

40. McMillan DGG, Marritt SJ, Firer-Sherwood MA, Shi L, Richardson DJ, Evans SD, Elliott SJ, Butt JN, Jeuken LJC. Protein-protein interaction regulates the direction of catalysis and electron transfer in a redox enzyme complex. J Am Chem Soc. 2013;135(28):10550-6.

41. Hartshorne RS, Reardon CL, Ross D, Nuester J, Clarke TA, Gates AJ, Mills PC, Fredrickson JK, Zachara JM, Shi L, Beliaev AS, Marshall MJ, Tien M, Brantley S, Butt JN, Richardson DJ. Characterization of an electron conduit between bacteria and the extracellular environment. Proc Natl Acad Sci USA. 2009;106(52):22169-74.

42. Richardson DJ, Butt JN, Fredrickson JK, Zachara JM, Shi L, Edwards MJ White G, Baiden N, Gates AJ, Marritt SJ, Clarke TA. The porin-cytochrome model for microbe-to-mineral electron transfer. Mol Microbiol. 2012;85(2):201-12.

43. White GF, Shi Z, Shi L, Wang ZM, Dohnalkova AC, Marshall MJ, Fredrickson JK, Zachara JM, Butt JN, Richardson DJ, Clarke TA. Rapid electron exchange between surface-exposed bacterial cytochromes and Fe(III) minerals. Proc Natl Acad Sci USA. 2013;110(16):6346-51.

44. Lower BH, Shi L, Yongsunthon R, Droubay TC, McCready DE, Lower SK. Specific bonds between an iron oxide surface and outer membrane cytochromes MtrC and OmcA from Shewanella oneidensis MR-1. J Bacteriol. 2007;189(13):4944-52.

45. Wu X, Zou L, Huang Y, Qiao Y, Long Z-e, Liu H, Li CM. Shewanella putrefaciens CN32 outer membrane cytochromes MtrC and UndA reduce electron shuttles to produce electricity in microbial fuel cells. Enzyme Microb Technol. 2018;115:23-8.

46. Marsili E, Baron DB, Shikhare ID, Coursolle D, Gralnick JA, Bond DR Shewanella secretes flavins that mediate extracellular electron transfer. Proc Natl Acad Sci USA. 2008;105(10):3968-73.

47. Kotloski NJ, Gralnick JA. Flavin electron shuttles dominate extracellular electron transfer by Shewanella oneidensis. MBio. 2013;4(1):e00553-e612.

48. Coursolle D, Baron DB, Bond DR, Gralnick JA. The Mtr respiratory pathway is essential for reducing flavins and electrodes in Shewanella oneidensis. J Bacteriol. 2010;192(2):467-74.

49. Okamoto A, Hashimoto K, Nealson KH, Nakamura R. Rate enhancement of bacterial extracellular electron transport involves bound flavin semiquinones. Proc Natl Acad Sci USA. 2013;110(19):7856-61.

50. Okamoto A, Hashimoto K, Nealson KH. Flavin redox bifurcation as a mechanism for controlling the direction of electron flow during extracellular electron transfer. Angew Chem Int Edit. 2014;53(41):10988-91.

51. Liu YM, Wang ZM, Liu J, Levar C, Edwards MJ, Babauta JT, Kennedy DW, Shi Z, Beyenal H, Bond DR, Clarke TA, Butt JN, Richardson DJ, Rosso KM, Zachara JM, Fredrickson JK, Shi L. A trans-outer membrane porincytochrome protein complex for extracellular electron transfer by Geobacter sulfurreducens PCA. Environ Microbiol Rep. 2014;6(6):776-85.

52. Ueki T. Cytochromes in extracellular electron transfer in Geobacter. Appl Environ Microbiol. 2021. https://doi.org/10.1128/AEM.03109-20.

53. Nevin KP, Kim BC, Glaven RH, Johnson JP, Woodard TL, Methe BA, DiDonato RJ, Covalla SF, Franks AE, Liu A, Lovley DR. Anode biofilm transcriptomics reveals outer surface components essential for high density current production in Geobacter sulfurreducens fuel cells. PLoS ONE. 2009;4(5):e5628.

54. Richter H, Nevin KP, Jia HF, Lowy DA, Lovley DR, Tender LM. Cyclic voltammetry of biofilms of wild type and mutant Geobacter sulfurreducens on fuel cell anodes indicates possible roles of OmcB, OmcZ, type IV pili, and protons in extracellular electron transfer. Energ Environ Sci. 2009;2(5):506-16.

55. Malvankar NS, Vargas M, Nevin K, Tremblay P-L, Evans-Lutterodt K, Nykypanchuk D, Martz E, Tuominen MT, Lovley DR. Structural basis for metallic-like conductivity in microbial nanowires. MBio. 2015;6(2):e00084-e115.

56. Reguera G, McCarthy KD, Mehta T, Nicoll JS, Tuominen MT, Lovley DR. Extracellular electron transfer via microbial nanowires. Nature. 2005:435(7045):1098-101.

57. Xiao Y, Zhao F. Electrochemical roles of extracellular polymeric substances in biofilms. Curr Opin Electrochem. 2017:4(1):206-11.

58. Cao B, Shi L, Brown RN, Xiong Y, Fredrickson JK, Romine MF, Marshall MJ, Lipton MS, Beyenal H. Extracellular polymeric substances from Shewanella sp HRCR-1 biofilms: characterization by infrared spectroscopy and proteomics. Environ Microbiol. 2011;13(4):1018-31.

59. Xiao Y, Zhang EH, Zhang JD, Dai YF, Yang ZH, Christensen HEM, Ulstrup J, Zhao F. Extracellular polymeric substances are transient media for microbial extracellular electron transfer. Sci Adv. 2017:3(7):e1700623.

60. Li S-W, Sheng G-P, Cheng Y-Y, Yu H-Q. Redox properties of extracellular polymeric substances (EPS) from electroactive bacteria. Sci Rep. 2016:6:3735.

61. Yan L, Zhang S, Chen P, Liu H, Yin H, Li H. Magnetotactic bacteria, magnetosomes and their application. Microbiol Res. 2012;167(9):507-19.

62. Nancharaiah YV, Mohan SV, Lens PNL. Metals removal and recovery in bioelectrochemical systems: a review. Bioresource Technol. 2015:195:102-14.

63. Azharuddin M, Zhu GH, Das D, Ozgur E, Uzun L, Turner APF, Patra HK. A repertoire of biomedical applications of noble metal nanoparticles. Chem Commun. 2019:55(49):6964-96.

64. Chen Z, Silveira GDQ, Ma X, Xie Y, Wu YA, Barry E, Rajh T, Fry HC, Laible PD, Rozhkova EA. Light-gated synthetic protocells for plasmonenhanced chemiosmotic gradient generation and ATP synthesis. Angew Chem Int Edit. 2019;58(15):4896-900.

65. Bao ZQ, Lan CQ. Advances in biosynthesis of noble metal nanoparticles mediated by photosynthetic organisms-a review. Colloid Surfaces B. 2019;184:110519.

66. Ishiki K, Okada K, Le DQ, Shiigi H, Nagaoka T. Investigation concerning the formation process of gold nanoparticles by Shewanella oneidensis MR-1. Anal Sci. 2017;33(2):129-31. 
67. Wu R, Cui L, Chen L, Wang C, Cao C, Sheng G, Yu H, Zhao F. Effects of bio-Au nanoparticles on electrochemical activity of Shewanella oneidensis wild type and $\triangle$ omcA/mtrC mutant. Sci Rep. 2013;3:3307.

68. Varia JC, Zegeye A, Velasquez-Orta S, Bull S. Process analysis of $\mathrm{AuCl}_{4}$-sorption leading to gold nanoparticle synthesis by Shewanella putrefaciens. Chem Eng J. 2016;288:482-8.

69. Zhu N, Cao Y, Shi C, Wu P, Ma H. Biorecovery of gold as nanoparticles and its catalytic activities for p-nitrophenol degradation. Environ Sci Pollut Res. 2016;23(8):7627-38.

70. Zhang $\mathrm{H}, \mathrm{Hu}$ X. Biosynthesis of Au nanoparticles by a marine bacterium and enhancing their catalytic activity through metal ions and metal oxides. Biotechnol Progr. 2019;35(2):e2727.

71. Borole AP, Reguera G, Ringeisen B, Wang Z-W, Feng Y, Kim BH. Electroactive biofilms: current status and future research needs. Energy Environ Sci. 2011;4(12):4813-34.

72. Slocik JM, Wright DW. Biomimetic mineralization of noble metal nanoclusters. Biomacromol. 2003;4(5):1135-41.

73. Chen M, Zhou XF, Liu X, Zeng RJ, Zhang F, Ye J, Zhou SG. Facilitated extracellular electron transfer of Geobacter sulfurreducens biofilm with in situ formed gold nanoparticles. Biosens Bioelectron. 2018;108:20-6.

74. Singh R, Shedbalkar UU, Wadhwani SA, Chopade BA. Bacteriagenic silver nanoparticles: synthesis, mechanism, and applications. Appl Microbiol Biotechnol. 2015;99(11):4579-93.

75. Li S-W, Zhang X, Sheng G-P. Silver nanoparticles formation by extracellular polymeric substances (EPS) from electroactive bacteria. Environ Sci Pollut Res. 2016;23(9):8627-33.

76. Zhang $X$, Yang C-W, Yu H-Q, Sheng G-P. Light-induced reduction of silver ions to silver nanoparticles in aquatic environments by microbial extracellular polymeric substances (EPS). Water Res. 2016;106:242-8.

77. Ng CK, Sivakumar K, Liu X, Madhaiyan M, Ji L, Yang L, Tang C, Song H, Kjelleberg S, Cao B. Influence of outer membrane c-type cytochromes on particle size and activity of extracellular nanoparticles produced by Shewanella oneidensis. Biotechnol Bioeng. 2013;110(7):1831-7.

78. Iqbal M, Kaneti YV, Kim J, Yuliarto B, Kang YM, Bando Y, Sugahara Y, Yamauchi Y. Chemical design of palladium-based nanoarchitectures for catalytic applications. Small. 2019;15(6):1804378.

79. De Windt W, Aelterman P, Verstraete W. Bioreductive deposition of palladium(0) nanoparticles on Shewanella oneidensis with catalytic activity towards reductive dechlorination of polychlorinated biphenyls. Environ Microbiol. 2005;7(3):314-25

80. De Windt W, Boon N, Van den Bulcke J, Rubberecht L, Prata F, Mast J, Hennebel T, Verstraete W. Biological control of the size and reactivity of catalytic $\mathrm{Pd}(0)$ produced by Shewanella oneidensis. Anton Leeuw Int J Gen Mol Microbiol. 2006;90(4):377-89.

81. Dundas CM, Graham AJ, Romanovicz DK, Keitz BK. Extracellular electron transfer by Shewanella oneidensis controls palladium nanoparticle phenotype. ACS Synth Biol. 2018;7(12):2726-36.

82. Pat-Espadas AM, Razo-Flores E, Rene Rangel-Mendez J, Cervantes FJ. Reduction of palladium and production of nano-catalyst by Geobacter sulfurreducens. Appl Microbiol Biotechnol. 2013;97(21):9553-60.

83. Pat-Espadas AM, Razo-Flores E, Rene Rangel-Mendez J, Cervantes FJ. Direct and quinone-mediated palladium reduction by Geobacter sulfurreducens: mechanisms and modeling. Environ Sci Technol. 2014;48(5):2910-9.

84. Hernandez-Eligio A, Pat-Espadas AM, Vega-Alvarado L, Huerta-Amparan M, Cervantes FJ, Juarez K. Global transcriptional analysis of Geobacter sulfurreducens under palladium reducing conditions reveals new key cytochromes involved. Appl Microbiol Biotechnol. 2020;104(9):4059-69.

85. Zannoni D, Borsetti F, Harrison JJ, Turner RJ. The bacterial response to the chalcogen metalloids Se and Te. Adv Microb Physiol. 2007;53(312):1-71.

86. Klonowska A, Heulin T, Vermeglio A. Selenite and tellurite reduction by Shewanella oneidensis. Appl Environ Microbiol. 2005;71(9):5607-9.

87. Li D-B, Cheng Y-Y, Wu C, Li W-W, Li N, Yang Z-C, Tong Z-H, Yu H-Q. Selenite reduction by Shewanella oneidensis MR-1 is mediated by fumarate reductase in periplasm. Sci Rep. 2014:4:3735.

88. Xia Z-C, Cheng Y-Y, Kong W-Q, Shi X-Y, Yang T, Wang M-Y, Huang F, Wu C. Electron shuttles alter selenite reduction pathway and redistribute formed Se(0) nanoparticles. Process Biochem. 2016;51(3):408-13.
89. Lee J-H, Han J, Choi H, Hur H-G. Effects of temperature and dissolved oxygen on Se(IV) removal and $\mathrm{Se}(0)$ precipitation by Shewanella sp HN-41. Chemosphere. 2007;68(10):1898-905.

90. Ho CT, Kim JW, Kim WB, Song K, Kanaly RA, Sadowsky MJ, Hur H-G. Shewanella-mediated synthesis of selenium nanowires and nanoribbons. J Mater Chem. 2010;20(28):5899-905.

91. Soda S, Ma W, Kuroda M, Nishikawa H, Zhang Y, Ike M. Characterization of moderately halotolerant selenate- and tellurite-reducing bacteria isolated from brackish areas in Osaka. Biosci Biotechnol Biochem. 2018;82(1):173-81.

92. Valdivia-Gonzalez MA, Diaz-Vasquez WA, Ruiz-Leon D, Becerra AA Aguayo DR, Perez-Donoso JM, Vasquez CC. A comparative analysis of tellurite detoxification by members of the genus Shewanella. Arch Microbiol. 2018:200(2):267-73.

93. Kim D-H, Kanaly RA, Hur H-G. Biological accumulation of tellurium nanorod structures via reduction of tellurite by Shewanella oneidensis MR-1. Bioresource Technol. 2012;125:127-31.

94. Kim D-H, Kim M-G, Jiang S, Lee J-H, Hur H-G. Promoted reduction of tellurite and formation of extracellular tellurium nanorods by concerted reaction between iron and Shewanella oneidensis MR-1. Environ Sci Technol. 2013;47(15):8709-15.

95. Pearce Cl, Pattrick RAD, Law N, Charnock JM, Coker VS, Fellowes JW, Oremland RS, Lloyd JR. Investigating different mechanisms for biogenic selenite transformations: Geobacter sulfurreducens, Shewanella oneidensis and Veillonella atypica. Environ Technol. 2009;30(12):1313-26.

96. Vaigankar DC, Dubey SK, Mujawar SY, D'Costa A, Shyama SK. Tellurite biotransformation and detoxification by Shewanella baltica with simultaneous synthesis of tellurium nanorods exhibiting photo-catalytic and anti-biofilm activity. Ecotox Environ Safe. 2018:165:516-26.

97. Tam K, Ho CT, Lee J-H, Lai M, Chang CH, Rheem Y, Chen W, Hur H-G, Myung NV. Growth mechanism of amorphous selenium nanoparticles synthesized by Shewanella sp HN-41. Biosci Biotechnol Biochem. 2010;74(4):696-700.

98. Kim MG, Kim D-H, Kim T, Park S, Kwon G, Kim MS, Shin TJ, Ahn H, Hur H-G. Unusual Li-ion storage through anionic redox processes of bacteria-driven tellurium nanorods. J Mater Chem A. 2015;3(33):16978-87.

99. Jahan MI, Tobe R, Mihara H. Characterization of a novel porin-Like protein, Extl, from Geobacter sulfurreducens and its implication in the reduction of selenite and tellurite. Inte J Mol Sci. 2018;19(3):809.

100. Jahan MI, Juengwiwattanakitti P, Izu Y, Tobe R, Imai T, Mihara H. Selenite uptake by outer membrane porin Extl and its involvement in the subcellular localization of rhodanese-like lipoprotein $\mathrm{ExtH}$ in Geobacter sulfurreducens. Biochem Biophys Res Commun. 2019;516(2):474-9.

101. Gawande MB, Goswami A, Felpin F-X, Asefa T, Huang X, Silva R, Zou $X$, Zboril R, Varma RS. Cu and Cu-Based Nanoparticles: synthesis and applications in review catalysis. Chem Rev. 2016;116(6):3722-811.

102. Ghosh S. Copper and palladium nanostructures: a bacteriogenic approach. Appl Microbiol Biotechnol. 2018;102(18):7693-701.

103. Kimber RL, Lewis EA, Parmeggiani F, Smith K, Bagshaw H, Starborg T, Joshi N, Figueroa Al, van der Laan G, Cibin G, Gianolio D, Haigh SJ, Pattrick RAD, Turner NJ, Lloyd JR. Biosynthesis and characterization of copper nanoparticles using Shewanella oneidensis: application for click chemistry. Small. 2018:14(10):1703145.

104. Lv Q, Zhang B, Xing X, Zhao Y, Cai R, Wang W, Gu Q. Biosynthesis of copper nanoparticles using Shewanella loihica PV-4 with antibacterial activity: novel approach and mechanisms investigation. J Hazard Mater. 2018;347:141-9.

105. Li C-X, Huang R-t, Shi X-y. Biosynthesis of Cu nanoparticles supported on carbon nanotubes and its catalytic performance under different test conditions. J Chem Technol Biotechnol. 2020:95(5):1511-8.

106. Gilroy KD, Ruditskiy A, Peng H-C, Qin D, Xia Y. Bimetallic nanocrystals: syntheses, properties, and applications. Chem Rev. 2016;116(18):10414-72.

107. Wang YX, Cao L, Libretto NJ, Li X, Li CY, Wan YD, He CN, Lee J, Gregg J, Zong H, Su D, Miller JT, Mueller T, Wang C. Ensemble effect in bimetallic electrocatalysts for $\mathrm{CO}_{2}$ reduction. J Am Chem Soc. 2019;141(42):16635-42.

108. Zhu WX, Yuan H, Liao F, Shen YW, Shi HX, Shi YD, Xu L, Ma MJ, Shao MW. Strain engineering for Janus palladium-gold bimetallic nanoparticles: enhanced electrocatalytic performance for oxygen reduction reaction and zinc-air battery. Chem Eng J. 2020;389:124240. 
109. Dobrovetska O, Saldan I, Orovcik L, Karlsson D, Sahlberg MH, Semenyuk Y, Pereviznyk O, Reshetnyak O, Kuntyi O, Mertsalo I, Serkiz R, Stelmakhovych B. Electrocatalytic activity of Pd-Au nanoalloys during methanol oxidation reaction. Int J Hydrogen Energ. 2020:45(7):4444-56.

110. Li H, Guo SJ, Shin K, Wong MS, Henkelman G. Design of a Pd-Au nitrite reduction catalyst by identifying and optimizing active ensembles. ACS Catal. 2019;9(9):7957-66.

111. Ju J, Liu XJ, Yu JJ, Sun K, Fathi F, Zeng XQ. Electrochemistry at bimetallic $\mathrm{Pd} / \mathrm{Au}$ thin film surfaces for selective detection of reactive oxygen species and reactive nitrogen species. Anal Chem. 2020;92(9):6538-47.

112. Hosseinkhani B, Sobjerg LS, Rotaru A-E, Emtiazi G, Skrydstrup T, Meyer RL. Microbially supported synthesis of catalytically active bimetallic Pd-Au nanoparticles. Biotechnol Bioeng. 2012;109(1):45-52.

113. Xu H, Xiao Y, Xu M, Cui H, Tan L, Feng N, Liu X, Qiu G, Dong H, Xie J, Microbial synthesis of Pd-Pt alloy nanoparticles using Shewanella oneidensis MR-1 with enhanced catalytic activity for nitrophenol and azo dyes reduction. Nanotechnology. 2019;30(6):065607.

114. Byrne JM, Klueglein N, Pearce C, Rosso KM, Appel E, Kappler A. Redox cycling of Fe(II) and Fe(III) in magnetite by Fe-metabolizing bacteria. Science. 2015:347(6229):1473-6.

115. Liu SX, Yu B, Wang S, Shen YQ, Cong HL. Preparation, surface functionalization and application of $\mathrm{Fe}_{3} \mathrm{O}_{4}$ magnetic nanoparticles. Adv Colloid Interface Sci. 2020;281:102165.

116. Gobbo OL, Sjaastad K, Radomski MW, Volkov Y, Prina-Mello A. Magnetic nanoparticles in cancer theranostics. Theranostics. 2015;5(11):1249-63.

117. Tang CL, He ZY, Liu HM, Xu YY, Huang H, Yang GJ, Xiao ZQ, Li S, Liu HN, Deng Y, Chen Z, Chen H, He NY. Application of magnetic nanoparticles in nucleic acid detection. J Nanobiotechnol. 2020;18(1):62.

118. Gloag L, Mehdipour M, Chen DF, Tilley RD, Gooding JJ. Advances in the application of magnetic nanoparticles for sensing. Adv Mater. 2019;31(48):1904385.

119. Piepenbrock A, Dippon U, Porsch K, Appel E, Kappler A. Dependence of microbial magnetite formation on humic substance and ferrihydrite concentrations. Geochim Et Cosmochim Acta. 2011;75(22):6844-58.

120. Jeong M, Kim Y, Roh Y. Biogenesis of magnetite nanoparticles using Shewanella species isolated from diverse regions. J Nanosci Nanotechnol. 2019;19(2):963-6.

121. Lee $\mathrm{J}-\mathrm{H}$, Roh $\mathrm{Y}, \mathrm{Hur} \mathrm{H}-\mathrm{G}$. Microbial production and characterization of superparamagnetic magnetite nanoparticles by Shewanella sp HN-41. J Microbiol Biotechnol. 2008;18(9):1572-7.

122. Lee J-H, Roh Y, Kim K-W, Hur H-G. Organic acid-dependent iron mineral formation by a newly isolated iron-reducing bacterium, Shewanella sp HN-41. Geomicrobiol J. 2007;24(1):31-41.

123. Wu W, Li B, Hu J, Li J, Wang F, Pan Y. Iron reduction and magnetite biomineralization mediated by a deep-sea iron-reducing bacterium Shewanella piezotolerans WP3. J Geophys Res Biogeosci. 2011;116:G04034.

124. Coker VS, Bell AMT, Pearce CI, Pattrick RAD, van der Laan G, Lloyd JR. Time-resolved synchrotron powder $X$-ray diffraction study of magnetite formation by the Fe(III)-reducing bacterium Geobacter sulfurreducens. Am Mineralogist. 2008;93(4):540-7.

125. Coker VS, Bennett JA, Telling ND, Henkel T, Charnock JM, van der Laan G, Pattrick RAD, Pearce Cl, Cutting RS, Shannon IJ, Wood J, Arenholz E, Lyon IC, Lloyd JR. Microbial engineering of nanoheterostructures: biological synthesis of a magnetically recoverable palladium nanocatalyst. ACS Nano. 2010;4(5):2577-84.

126. Byrne JM, Telling ND, Coker VS, Pattrick RAD, van der Laan G, Arenholz E, Tuna F, Lloyd JR. Control of nanoparticle size, reactivity and magnetic properties during the bioproduction of magnetite by Geobacter sulfurreducens. Nanotechnology. 2011;22(45):455709.

127. Byrne JM, Coker VS, Cespedes E, Wincott PL, Vaughan DJ, Pattrick RAD, van der Laan G, Arenholz E, Tuna F, Bencsik M, Lloyd JR, Telling ND. Biosynthesis of zinc substituted magnetite nanoparticles with enhanced magnetic properties. Adv Funct Mater. 2014;24(17):2518-29.

128. Cespedes E, Byrne JM, Farrow N, Moise S, Coker VS, Bencsik M, Lloyd JR, Telling ND. Bacterially synthesized ferrite nanoparticles for magnetic hyperthermia applications. Nanoscale. 2014;6(21):12958-70.

129. Byrne JM, Muhamadali H, Coker VS, Cooper J, Lloyd JR. Scale-up of the production of highly reactive biogenic magnetite nanoparticles using Geobacter sulfurreducens. J R Soc Interface. 2015;12(107):20150240.
130. Joshi N, Filip J, Coker VS, Sadhukhan J, Safarik I, Bagshaw H, Lloyd JR. Microbial reduction of natural Fe(III) minerals; toward the sustainable production of functional magnetic nanoparticles. Front Environ Sci. 2018;6:127.

131. Sundman A, Vitzthum A-L, Adaktylos-Surber K, Figueroa Al, van der Laan G, Daus B, Kappler A, Byrne JM. Effect of Fe-metabolizing bacteria and humic substances on magnetite nanoparticle reactivity towards arsenic and chromium. J Hazard Mater. 2020;384:121450.

132. Coker VS, Telling ND, van der Laan G, Pattrick RAD, Pearce Cl, Arenholz E, Tuna F, Winpenny REP, Lloyd JR. Harnessing the extracellular bacterial production of nanoscale cobalt ferrite with exploitable magnetic properties. ACS Nano. 2009;3(7):1922-8.

133. Watts MP, Cutting RS, Joshi N, Coker VS, Mosberger A, Zhou B, Davies $C M$, van Dongen BE, Hoffstetter T, Lloyd JR. Highly efficient degradation of organic pollutants using a microbially-synthesized nanocatalyst. Int Biodeter Biodegr. 2017;119:155-61.

134. Feng YY, Marusak KE, You LC, Zauscher S. Biosynthetic transition metal chalcogenide semiconductor nanoparticles: progress in synthesis, property control and applications. Curr Opin Colloid Interface Sci. 2018:38:190-203.

135. Jacob JM, Lens PNL, Balakrishnan RM. Microbial synthesis of chalcogenide semiconductor nanoparticles: a review. Microb Biotechnol. 2016;9(1):11-21.

136. Perry KA, Kostka JE, Luther GW 3rd, Nealson KH. Mediation of sulfur speciation by a black sea facultative anaerobe. Science. 1993;259(5096):801-3.

137. Moser DP, Nealson KH. Growth of the facultative anaerobe Shewanella putrefaciens by elemental sulfur reduction. Appl Environ Microbiol. 1996;62(6):2100-5.

138. Burns JL, DiChristina TJ. Anaerobic respiration of elemental sulfur and thiosulfate by Shewanella oneidensis MR-1 requires psrA, a homolog of the phsA gene of Salmonella enterica serovar Typhimurium LT2. Appl Environ Microbiol. 2009;75(16):5209-17.

139. Shirodkar S, Reed S, Romine M, Saffarini D. The octahaem SirA catalyses dissimilatory sulfite reduction in Shewanella oneidensis MR-1. Environ Microbiol. 2011;13(1):108-15.

140. Jiang S, Liu F, Kim M-G, Lim J-H, Lee K-J, Choa Y-H, Song K, Sadowsky MJ, Chen W, Myung NV, Hur H-G. Synthesis of chalcogenide ternary and quaternary nanotubes through directed compositional alterations of bacterial As-S nanotubes. J Mater Chem. 2011;21(28):10277-9.

141. Kim T-Y, Ahn H, Jeon J, Kim MS, Kim MG, Hur H-G. Biogenic realgar $\mathrm{As}_{4} \mathrm{~S}_{4}$ molecular clusters formed by a one-pot microbial-driven process as a Li-ion storage material. Adv Sustain Syst. 2017;1 (7):1700056.

142. McFarlane IR, Lazzari-Dean JR, El-Naggar MY. Field effect transistors based on semiconductive microbially synthesized chalcogenide nanofibers. Acta Biomater. 2015;13:364-73.

143. Nakamura R, Okamoto A, Tajima N, Newton GJ, Kai F, Takashima T, Hashimoto K. Biological iron-monosulfide production for efficient electricity harvesting from a deep-sea metal-reducing bacterium. ChemBioChem. 2010;11(5):643-5.

144. Kondo K, Okamoto A, Hashimoto K, Nakamura R. Sulfur-mediated electron shuttling sustains microbial long-distance extracellular electron transfer with the aid of metallic iron sulfides. Langmuir. 2015;31(26):7427-34.

145. Flynn TM, O'Loughlin EJ, Mishra B, DiChristina TJ, Kemner KM. Sulfurmediated electron shuttling during bacterial iron reduction. Science. 2014;344(6187):1039-42.

146. Huo Y-C, Li W-W, Chen C-B, Li C-X, Zeng R, Lau T-C, Huang T-Y. Biogenic FeS accelerates reductive dechlorination of carbon tetrachloride by Shewanella putrefaciens CN32. Enzyme Microb Technol. 2016;95:236-41.

147. Nie Z, Wang N, Xia X, Xia J, Liu H, Zhou Y, Deng Y, Xue Z. Biogenic FeS promotes dechlorination and thus de-cytotoxity of trichloroethylene. Bioproc Biosyst Eng. 2020;43:1791.

148. Yu Y-Y, Cheng Q-W, Sha C, Chen Y-X, Naraginti S, Yong Y-C. Sizecontrolled biosynthesis of FeS nanoparticles for efficient removal of aqueous Cr(VI). Chem Eng J. 2020:379:122404.

149. Xiao X, Zhu W-W, Yuan H, Li W-W, Li Q, Yu H-Q. Biosynthesis of FeS nanoparticles from contaminant degradation in one single system. Biochem Eng J. 2016;105:214-9.

150. Suresh AK, Doktycz MJ, Wang W, Moon J-W, Gu B, Meyer HM III, Hensley DK, Allison DP, Phelps TJ, Pelletier DA. Monodispersed biocompatible 
silver sulfide nanoparticles: facile extracellular biosynthesis using the gamma-proteobacterium Shewanella oneidensis. Acta Biomater. $2011 ; 7(12): 4253-8$.

151. Voeikova TA, Shebanova AS, Ivanov YD, Kaysheva AL, Novikova LM, Zhuravliova OA, Shumyantseva WV, Shaitan KV, Kirpichnikov MP, Debabov VG. The role of roteins of the oter membrane of Shewanella oneidensis MR-1 in the formation and stabilization of silver sulfide nanoparticles. Appl Biochem Microbiol. 2016;52(8):769-75.

152. Zhou N-Q, Tian L-J, Wang Y-C, Li D-B, Li P-P, Zhang X, Yu H-Q. Extracellular biosynthesis of copper sulfide nanoparticles by Shewanella oneidensis MR-1 as a photothermal agent. Enzyme Microb Technol. 2016:95:230-5.

153. Xiao X, Liu Q-Y, Lu X-R, Li T-T, Feng X-L, Li Q, Liu Z-Y, Feng Y-J. Self-assembly of complex hollow CuS nano/micro shell by an electrochemically active bacterium Shewanella oneidensis MR-1. Int Biodeter Biodegr. 2017:116:10-6.

154. Xiao X, Ma X-B, Yuan H, Liu P-C, Lei Y-B, Xu H, Du D-L, Sun J-F, Feng Y-J. Photocatalytic properties of zinc sulfide nanocrystals biofabricated by metal-reducing bacterium Shewanella oneidensis MR-1. J Hazard Mater. 2015;288:134-9.

155. Chellamuthu P, Naughton K, Pirbadian S, Silva KPT, Chavez MS, ElNaggar MY, Boedicker J. Biogenic control of manganese doping in zinc sulfide nanomaterial using Shewanella oneidensis MR-1. Front Microbiol. 2019;10:938.

156. Zhang F, Yi DM, Sun HZ, Zhang H. Cadmium-based quantum dots: preparation, surface modification, and applications. J Nanosci Nanotechnol. 2014;14(2):1409-24.

157. Paula Vena M, Jobbagy M, Bilmes SA. Microorganism mediated biosynthesis of metal chalcogenides; a powerful tool to transform toxic effluents into functional nanomaterials. Sci Total Environ. 2016;565:804-10.

158. Wang L, Chen S, Ding Y, Zhu Q, Zhang N, Yu S. Biofabrication of morphology improved cadmium sulfide nanoparticles using Shewanella oneidensis bacterial cells and ionic liquid: For toxicity against brain cancer cell lines. J Photochem Photobiol B. 2018;178:424-7.

159. Xiao X, Han X, Wang L-G, Long F, Ma X-L, Xu C-C, Ma X-B, Wang C-X, Liu Z-Y. Anaerobically photoreductive degradation by CdS nanocrystal: biofabrication process and bioelectron-driven reaction coupled with Shewanella oneidensis MR-1. Biochem Eng J. 2020;154:107466.

160. Tian L-J, Li W-W, Zhu T-T, Chen J-J, Wang W-K, An P-F, Zhang L, Dong J-C, Guan Y, Liu D-F, Zhou N-Q, Liu G, Tian Y-C, Yu H-Q. Directed biofabrication of nanoparticles through regulating extracellular electron transfer. J Am Chem Soc. 2017;139(35):12149-52.

161. Mohanty A, Liu Y, Yang L, Cao B. Extracellular biogenic nanomaterials inhibit pyoverdine production in Pseudomonas aeruginosa: a novel insight into impacts of metal(loid)s on environmental bacteria. Appl Microbiol Biotechnol. 2015:99(4):1957-66.

162. Tuo Y, Liu G, Zhou J, Wang A, Wang J, Jin R, Lv H. Microbial formation of palladium nanoparticles by Geobacter sulfurreducens for chromate reduction. Bioresource Technol. 2013;133:606-11.

163. Wang W, Zhang B, Liu Q, Du P, Liu W, He Z. Biosynthesis of palladium nanoparticles using Shewanella loihica PV-4 for excellent catalytic reduction of chromium(VI). Environ Sci Nano. 2018;5(3):730-9.

164. Song X, Shi X. Biosynthesis of Ag/reduced graphene oxide nanocomposites using Shewanella oneidensis MR-1 and their antibacterial and catalytic applications. Appl Surface Sci. 2019;491:682-9.

165. Hou Y-N, Zhang B, Yun H, Yang Z-N, Han J-L, Zhou J, Wang A-J, Cheng $\mathrm{H}-\mathrm{Y}$. Palladized cells as suspension catalyst and electrochemical catalyst for reductively degrading aromatics contaminants: Roles of Pd size and distribution. Water Res. 2017;125:288-97.

166. Xiong L, Chen JJ, Huang YX, Li WW, Xie JF, Yu HQ. An oxygen reduction catalyst derived from a robust Pd-reducing bacterium. Nano Energy. 2015:12:33-42.

167. Song X, Shi X, Yang M. Dual application of Shewanella oneidensis MR-1 in green biosynthesis of $\mathrm{Pd}$ nanoparticles supported on $\mathrm{TiO}_{2}$ nanotubes and assisted photocatalytic degradation of methylene blue. IET Nanobiotechnol. 2018;12(4):441-5.

168. Han R, Song X, Wang Q, Qi Y, Deng G, Zhang A, Wang Q, Chang F, Wu C, Cheng Y. Microbial synthesis of graphene-supported highly-dispersed Pd-Ag bimetallic nanoparticles and its catalytic activity. J Chem Technol Biotechnol. 2019;94(10):3375-83.
169. Ho CT, Nguyen A-T, Duong T-T, Le T-P-Q, Dang D-K, Tang T-C, Hur H-G. Biologically based method for the synthesis of $\mathrm{Hg}$-Se nanostructures by Shewanella spp. RSC Adv. 2015;5(27):20764-8.

170. Novoselov KS, Geim AK, Morozov SV, Jiang D, Zhang Y, Dubonos SV, Grigorieva IV, Firsov AA. Electric field effect in atomically thin carbon films. Science. 2004;306(5696):666-9.

171. Yu XW, Cheng HH, Zhang M, Zhao Y, Qu LT, Shi GQ. Graphene-based smart materials. Nat Rev Mater. 2017;2(9):13.

172. De Silva KKH, Huang HH, Joshi RK, Yoshimura M. Chemical reduction of graphene oxide using green reductants. Carbon. 2017;119:190-9.

173. Zhang J, Yang H, Shen G, Cheng P, Zhang J, Guo S. Reduction of graphene oxide vial-ascorbic acid. Chem Commun. 2010;46(7):1112-4.

174. Jiao YQ, Qian F, Li Y, Wang GM, Saltikov CW, Gralnick JA. Deciphering the electron transport pathway for graphene oxide reduction by Shewanella oneidensis MR-1. J Bacteriol. 2011;193(14):3662-5.

175. Yu S-S, Chen J-J, Liu X-Y, Yu H-Q. Interfacial electron transfer from the outer membrane cytochrome OmcA to graphene oxide in a microbial fuel cell: spectral and electrochemical insights. ACS Energy Lett. 2018;3(10):2449-56.

176. Liu G, Zhang X, Zhou J, Wang A, Wang J, Lin R, Lv H. Quinone-mediated microbial synthesis of reduced graphene oxide with peroxidase-like activity. Bioresource Technol. 2013;149:503-8.

177. Wang G, Qian F, Saltikov CW, Jiao Y, Li Y. Microbial reduction of graphene oxide by Shewanella. Nano Res. 2011;4(6):563-70.

178. Vargas C, Simarro R, Alberto Reina J, Fernando Bautista L, Carmen Molina M, Gonzalez-Benitez N. New approach for biological synthesis of reduced graphene oxide. Biochem Eng J. 2019:151:107331.

179. Cong H-P, Chen J-F, Yu S-H. Graphene-based macroscopic assemblies and architectures: an emerging material system. Chem Soc Rev. 2014;43(21):7295-325

180. He $Y-R$, Cheng $Y-Y$, Wang W-K, Yu H-Q. A green approach to recover $\mathrm{Au}(\mathrm{III})$ in aqueous solution using biologically assembled $\mathrm{rGO}$ hydrogels. Chem Eng J. 2015;270:476-84.

181. Yoshida N, Miyata Y, Doi K, Goto Y, Nagao Y, Tero R, Hiraishi A. Graphene oxide-dependent growth and self-aggregation into a hydrogel complex of exoelectrogenic bacteria. Sci Rep. 2016;6:21867.

182. Dong B, Liu G, Zhou J, Wang A, Wang J, Jin R, Lv H. Biogenic gold nanoparticles-reduced graphene oxide nanohybrid: synthesis, characterization and application in chemical and biological reduction of nitroaromatics. RSC Adv. 2015;5(118):97798-806.

183. Wang W, Mi J-L, Shen Q-C, Yong Y-C. Shewanella oneidensis assisted biosynthesis of $\mathrm{Pd}$ /Reductive-graphene-oxide nanocomposites for oxygen reduction reaction. ChemistrySelect. 2020;5(11):3179-86.

184. Zou L, Huang Y, Wu X, Long Z-e. Synergistically promoting microbial biofilm growth and interfacial bioelectrocatalysis by molybdenum carbide nanoparticles functionalized graphene anode for bioelectricity production. J Power Sources. 2019:413:174-81.

185. Zou L, Lu Z, Huang Y, Long Z-e, Qiao Y. Nanoporous $\mathrm{Mo}_{2} \mathrm{C}$ functionalized 3D carbon architecture anode for boosting flavins mediated interfacial bioelectrocatalysis in microbial fuel cells. J Power Sources. 2017:359:549-55.

186. Lin T, Ding W, Sun L, Wang L, Liu C-G, Song H. Engineered Shewanella oneidensis-reduced graphene oxide biohybrid with enhanced biosynthesis and transport of flavins enabled a highest bioelectricity output in microbial fuel cells. Nano Energy. 2018;50:639-48.

187. Song TS, Zhang HK, Liu HX, Zhang DL, Wang HQ, Yang Y, Yuan H, Xie JJ. High efficiency microbial electrosynthesis of acetate from carbon dioxide by a self-assembled electroactive biofilm. Bioresource Technol. 2017;243:573-82.

188. Song TS, Jin YJ, Bao JJ, Kang DZ, Xie JJ. Graphene/biofilm composites for enhancement of hexavalent chromium reduction and electricity production in a biocathode microbial fuel cell. J Hazard Mater. 2016;317:73-80

189. Hou Y-N, Liu H, Han J-L, Cai WW, Zhou J, Wang A-J, Cheng H-Y. Electroactive biofilm serving as the green synthesizer and stabilizer for in situ fabricating 3D nanopalladium network: an efficient electrocatalyst. ACS Sustain Chem Eng. 2016;4(10):5392-7.

190. Hou Y-N, Sun S-Y, Yang Z-N, Yun H, Zhu T-t, Ma J-F, Han J-L, Wang A-J, Cheng $\mathrm{H}-\mathrm{Y}$. Shewanella oneidensis MR-1 self-assembled Pd-cells-rGO conductive composite for enhancing electrocatalysis. Environ Res. 2020;184:109317. 
191. Shi QR, Zhu CZ, Du D, Lin YH. Robust noble metal-based electrocatalysts for oxygen evolution reaction. Chem Soc Rev. 2019;48(12):3181-92.

192. Jiang C, Guo Z, Zhu Y, Liu H, Wan M, Jiang L. Shewanella-mediated biosynthesis of manganese oxide micro-/nanocubes as efficient electrocatalysts for the oxygen reduction reaction. Chemsuschem. 2015;8(1):158-63.

193. Song X, Shi X. Bioreductive deposition of highly dispersed Ag nanoparticles on carbon nanotubes with enhanced catalytic degradation for 4-nitrophenol assisted by Shewanella oneidensis MR-1. Environm Sci Pollut Res. 2017;24(3):3038-44.

194. Sultan S, Hasnain S. Reduction of toxic hexavalent chromium by Ochrobactrum intermedium strain SDCr-5 stimulated by heavy metals. Bioresource Technol. 2007;98(2):340-4.
195. Kim Y, Roh Y. Environmental application of biogenic magnetite nanoparticles to remediate chromium(III/VI)-contaminated water. Minerals. 2019;9(5):260.

196. Chernousova S, Epple M. Silver as antibacterial agent: ion, nanoparticle, and metal. Angew Chem Int Edit. 2013;52(6):1636-53.

\section{Publisher's Note}

Springer Nature remains neutral with regard to jurisdictional claims in published maps and institutional affiliations.
Ready to submit your research? Choose BMC and benefit from:

- fast, convenient online submission

- thorough peer review by experienced researchers in your field

- rapid publication on acceptance

- support for research data, including large and complex data types

- gold Open Access which fosters wider collaboration and increased citations

- maximum visibility for your research: over 100M website views per year

At BMC, research is always in progress.

Learn more biomedcentral.com/submissions 